\title{
An Experimental Study of Multi-Particle Dynamics in Triboelectrostatic Systems
}

Final Technical Report

by

Myung S. Jhon

Department of Chemical Engineering, Carnegie Mellon University, Pittsburgh, PA 15213

July 12,2001

Work performed under Contract No. DE-FG26-98FT40085

For:

U.S. Department of Energy

National Energy Technology Laboratory

626 Cochrans Mill Road

Pittsburgh, PA 15236-0940 


\section{Project Team Members}

- Dr. Myung S. Jhon (Professor)

- Stephen J. Vinay III (Graduate Student, currently working at Bettis Atomic Power Laboratory)

- Noshir Pesika (Undergraduate Student, currently graduate student at Johns Hopkins University)

- Charles M. Schroeder III (Undergraduate Student, currently graduate student at Stanford University) 


\begin{abstract}
Using state-of-the-art flow/particle visualization and animation techniques, the timedependent statistical distributions of charged-particle swarms exposed to external fields (both electrostatic and flow) are analyzed. We found that interparticle interaction and drag forces mainly influenced swarm dispersion in a Lagrangian reference frame, whereas the "average" particle trajectory was affected primarily by the external electric field.
\end{abstract}

\title{
1. Introduction
}

The phenomenon of frictional charging, triboelectrostatics was discovered in ancient times, when a piece of amber would attract small fragments of matter when rubbed with cloth or fur; however, the mechanism by which charge is transferred between substances is still not fully understood. Lowell and Rose-Inness ${ }^{1}$ provide an excellent review of the contact electrification of both metals and insulators, covering not only experimental methods in charge measurement, but also the three proposed mechanisms of frictional charging: material, ion, and electron transfer. Experimental studies based on charge density measurements ${ }^{2-6}$, including the variability of surface charge density with both chemical surface modification and increased sample purity, reveal that particle size and surface chemistry have a profound effect on the sign and magnitude of the induced charge. Models, which attempt to describe the rate and efficiency of tribocharging and are based primarily on the existence of surface acceptor/donor sites or "states", have been developed ${ }^{7-9}$, however these theories have failed to put the final stamp on the essence of frictional charging.

Triboelectrostatics has been applied successfully to the separation of entrained solid particulates ${ }^{10-15}$, including Edison's pioneering experiments ${ }^{10}$ in the separation of gold from quartz more than a century ago. Recently, the idea of triboelectrostatic separation has been expanded to include plastics recycling, the recovery of precious metals, and the beneficiation of power plant inlet and flue gas streams to reduce both burner downtime and particulate emissions to the environment. The inherent advantage in using triboelectrostatics for separation is that it is a dry technique, therefore cleaning/dewatering costs are avoided. 
The dynamics of entrained solids is of great interest in many areas, and a comprehensive theory that governs the coupling between fluid flows and solid particles remains elusive. It is well known that, when solid particles are entrained in liquids or gases, the particles exert a force on the fluid, and the fluid simultaneously exerts an equal and opposite force on the particles ${ }^{16-17}$, according to Newton's $3^{\text {rd }}$ Law. These forces, as well as the voids caused by the displacement of the fluid by solid particles, cause turbulent wakes in the flow. As a consequence of this induced turbulence, the trajectories of the entrained particles may be altered. For concentrated particle systems, these complex hydrodynamic disturbances can only be interpreted from a statistical viewpoint.

Gupta $^{18}$ believed that the external electric field force would dominate the drag and inertial forces in a dilute system, and he attempted to describe the particle concentration in a batch separator by diffusion. However, his oversimplified diffusion equation did not explicitly contain an electrostatic field term and failed to qualitatively describe experimental data.

We have analyzed the individual and average trajectories of triboelectrostatically-charged model particle distributions, or "swarms", inside of a wind tunnel. Laser Doppler velocimetry (LDV) was used to measure both the velocity and turbulence intensity of the entrained particles and the wind tunnel sweep gas. We have studied the effects of the externally-applied electric field, sweep gas velocity, particle injection velocity, and particle size on these trajectories and have found that each of these parameters has a significant effect on the separation. The effects of sweep gas velocity and external electric field are demonstrated in this paper. Similar to the Lagrangian reference frame, we follow the trajectory of the "average" particle, and we observe and qualitatively describe the effect of particle-particle interactions on the dynamics of the charged-particle swarms.

\section{Experimental}

The experimentation was performed at the Particle Flow Analysis Facility (PFAF) at the Federal Energy Technology Center (FETC) located in Bruceton, PA. The PFAF is equipped with a state-of-the-art flow visualization system designed to track particle trajectories, and LDV apparatus that has the ability to measure particle velocities and both sweep gas velocity and turbulence intensity. 
The separation zone, housed inside of a high-velocity wind tunnel, consists of a particle feeder, an injection nozzle, and two copper electrodes spaced 10 $\mathrm{cm}$ apart, as shown in Fig. 1. The optical train outside of the tunnel, including a 5-Watt argon ion laser (Spectra Physics), a plano-convex

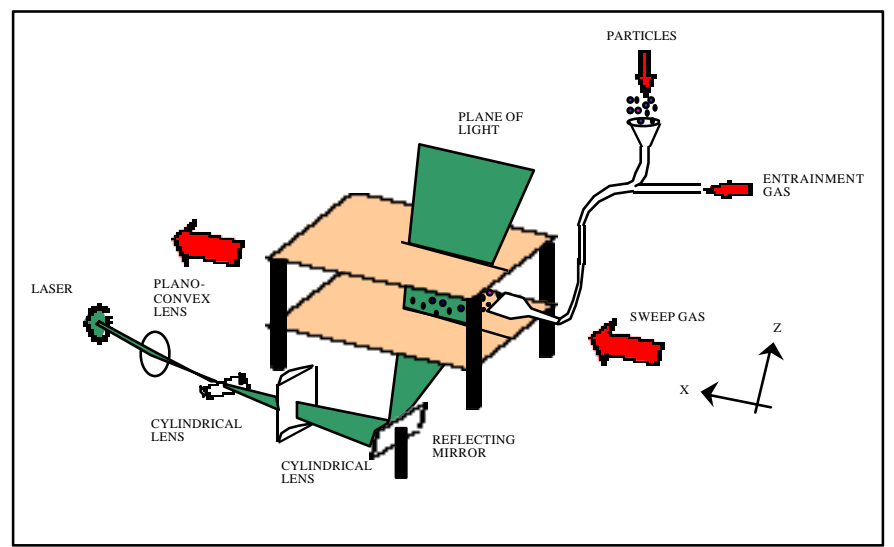

Figure 1. Illustration of the separation zone and vertical laser sheet lens, two cylindrical lenses, and a planar mirror, which illuminates the separation zone via a vertical laser sheet, can also be seen. Model particle systems, a combination of polyvinyl alcohol (PVA) particles, solid and hollow glass spheres, and/or silica gel (SG) particles, are fed to a copper pneumatic transport line and entrained in a flow of nitrogen gas. During transport, these particles collide with each other and the walls of the tube and become charged via frictional collisions. The positively-charged PVA and negatively-charged SG particles then flow past an in-line mixer (to enhance particle charging) to the nozzle, where they are injected between the copper electrodes, which support a DC voltage of up to $\pm 25,000 \mathrm{~V}$. The nozzle is located approximately $3 \mathrm{~cm}$ inside the leading edge of the electrodes to avoid the edge effects of the electric field.

Flow visualization data is acquired by a high-resolution digital camera, which sends digitized images of the particles flowing through the vertical laser sheet to a PC equipped with an image-grabber board. The camera is equipped with a zoom lens, and the rate of data acquisition is approximately one image per three seconds. The images are viewed with OPTIMAS $^{\odot}$ software, and a background image for each experiment was recorded and subtracted from the analyzed data. Pixel-by-pixel averaging of individual images is performed to analyze the evolution of the particle distribution through the separation zone, and slices are "cut" through the averaged plumes to extract the particle density distribution data. For each experiment, approximately 40 individual images were averaged. A typical individual image is shown in Fig. 2(a), and the associated "averaged" image with the drawn slices in Fig. 2(b). Note in Fig. 2 that the PVA particle trajectories can be seen easily, but the 
SG trajectories are barely seen due to the poor reflective properties of SG; however, the final deposition of SG particles on the top plate is clearly visible and able to be analyzed. It is also important to note that the intensity contribution of the SG particles must be subtracted from slices 1 to 3 (prior the separation plane) in analyzing the pure PVA plume.

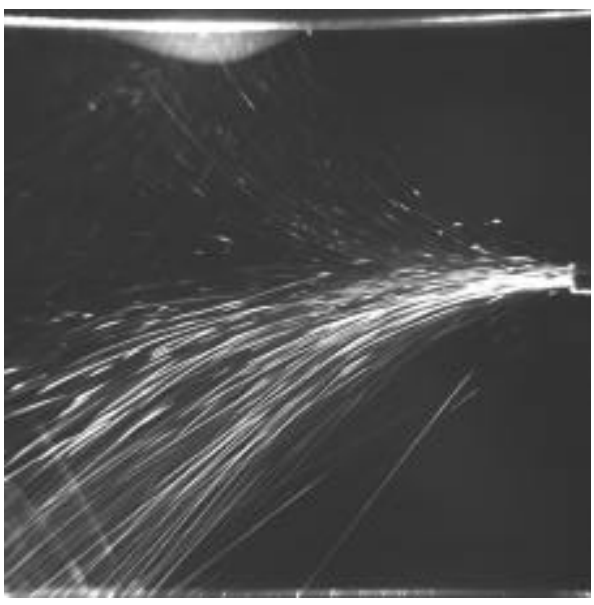

(a)

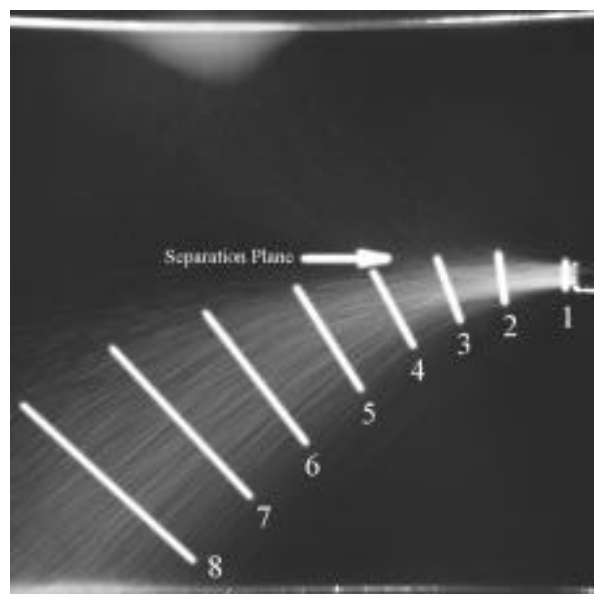

(b)

Figure 2. (a) Individual and (b) "averaged" images of charged particles in the separation zone.

Study of the behavior of particle distributions resulting from particle-particle interactions is essential in understanding the underlying mechanisms of particle "swarm" dynamics. The combined effect of three statistical distributions: initial velocity at the nozzle exit, particle size, and particle charge, affects how the swarm moves through the separation zone. Therefore, experimentation controlled these factors, as well as the influences of both the sweep gas and external electric field. Our focus on these issues differs from that of previous investigators, because we are more concerned with the fundamentals of the dynamics of particle clusters resulting from particle/flow couplings and interparticle interactions.

LDV was used to calibrate the seeded sweep gas flow in terms of both horizontal and vertical velocity and turbulence intensity. Note that finite turbulence intensity was detected near the nozzle and the electrodes in an otherwise-laminar flow. We then measured particle velocities exiting the nozzle. Figure 3 shows a representative data set of horizontal and vertical velocities using 45-63 $\mu \mathrm{m}$ glass beads, where $N$ is the number of particles with the given velocity. We see that the horizontal velocity profile for this representative run is unimodal 
with a mean of $3.472 \pm 0.529 \mathrm{~m} / \mathrm{s}$, and the vertical velocity profile is bimodal, very slightly skewed to negative values due to gravitational effects, and centered around zero.

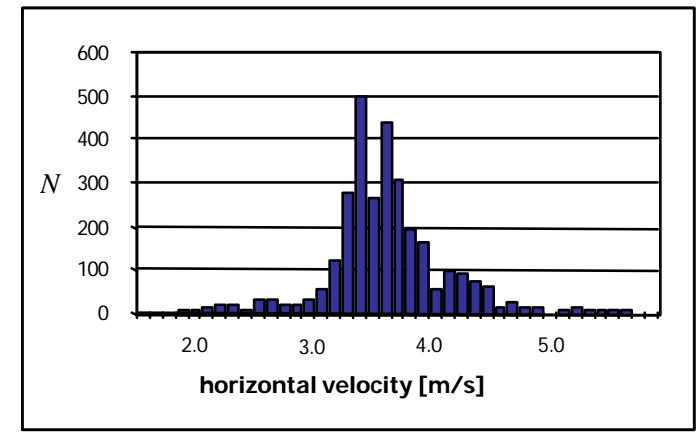

(a)

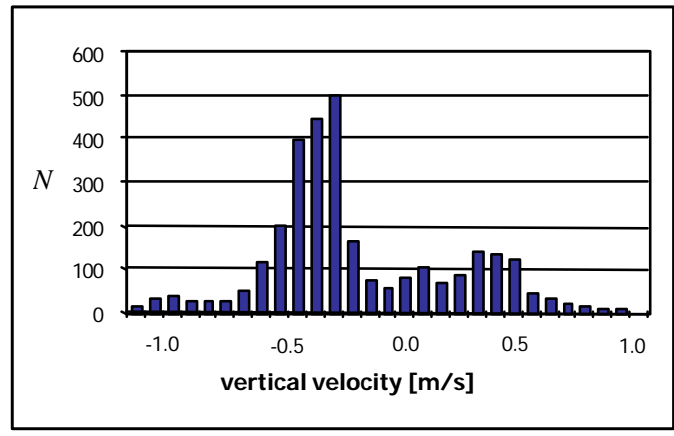

(b)

Figure 3. (a) Horizontal and (b) vertical particle velocity distributions at the nozzle exit.

Table 1 shows the particle distributions and conditions for four experimental data sets (denoted I-IV). Comparison of I and II illustrates the effect of the wind tunnel sweep velocity (drag force on the particles) on the swarm dynamics, while comparing III and IV examines how the externally-applied electric field influences the trajectories of the charged particles. Note that in I and II, the PVA and SG particles have the same mean diameter $(85 \mu \mathrm{m})$, whereas in III and IV, small PVA particles (45-75 $\mu \mathrm{m}$ diameter) are mixed with relatively large (210 $\mu \mathrm{m}$ diameter) SG particles.

Table 1. Experimental conditions for representative separations (shaded areas are controlled conditions).

\begin{tabular}{|c|c|c|c|c|}
\hline Experiment & $\begin{array}{c}\text { Sweep Gas } \\
\text { Velocity [m/s] }\end{array}$ & $\begin{array}{c}\text { Particle Injection } \\
\text { Velocity [m/s] }\end{array}$ & $\begin{array}{c}\text { External Electric } \\
\text { Field Potential [V] }\end{array}$ & $\begin{array}{c}\text { Particle Size/Size } \\
\text { Distribution }\end{array}$ \\
\hline I & 1.058 & 2.694 & $\pm 2.5 \times 10^{4}$ & $\begin{array}{c}50 \mathrm{wt} \%, 85 \mu \mathrm{m} \\
\text { SG \& PVA }\end{array}$ \\
\hline II & 2.739 & 2.694 & $\pm 2.5 \times 10^{4}$ & $\begin{array}{c}50 \mathrm{wt} \%, 85 \mu \mathrm{m} \\
\text { SG \& PVA }\end{array}$ \\
\hline III & 0.413 & 3.472 & $\pm 2.5 \times 10^{4}$ & $\begin{array}{c}10 \mathrm{wt} \% 210 \mu \mathrm{m} \mathrm{SG} \\
45-75 \mu \mathrm{m} \text { PVA }\end{array}$ \\
\hline IV & 0.413 & 3.472 & 0 & $10 \mathrm{wt} \% 210 \mu \mathrm{m} \mathrm{SG}$ \\
$45-75 \mu \mathrm{m}$ PVA
\end{tabular}




\section{Data Analysis}

To illustrate the details of the swarm dynamics effectively, Figs. 3(a)-(j) show 10 animated frames derived from the averaged image of I, shown in Fig. 2(a) and described in Table 1. Note that the slices in the animation are cut at equal intervals along the horizontal axis.

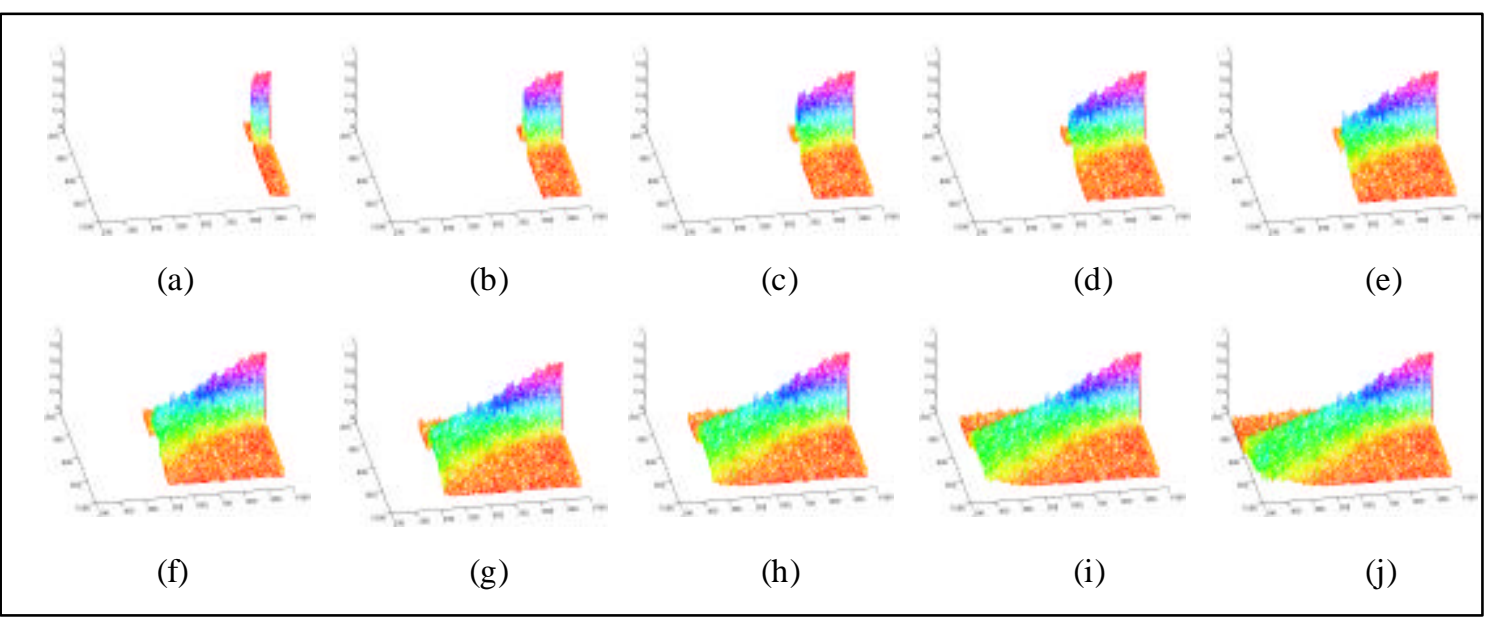

Figure 3. Ten animated frames showing the evolution of the particle density distribution

For each of the experiments given in Table 1, an averaged image was created and slices cut perpendicular to the "average" particle trajectory so that we could analyze the evolution of the particle density distribution. Figure 4 shows the fitted Gaussian curves for slices 2 through 7 from Fig. 2(b). The intensity values given on the vertical axis of the graph in Fig. 4 are proportional to the number

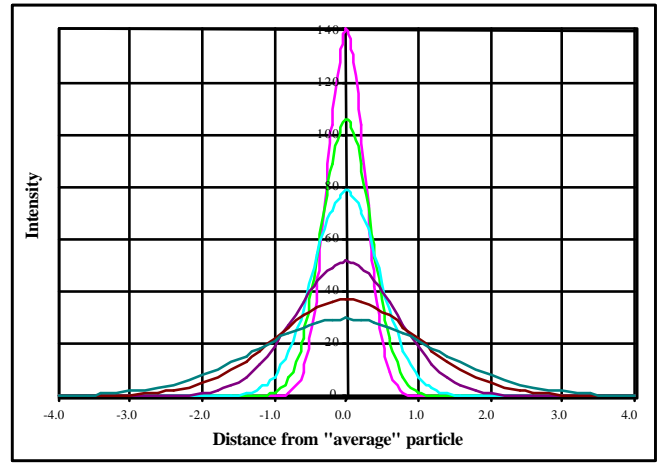

Figure 4. Gaussian fits for slices 2 through 7 shown in Fig. 2(b) density of particles at that point. 


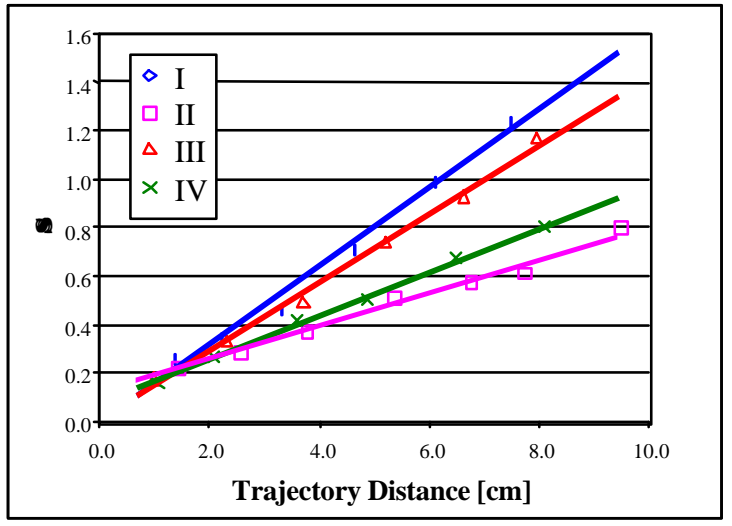

Figure 5. Linear relationship between $\sigma$ and trajectory distance, $\left|\mathbf{r}_{\mathrm{m}}\right|$
For the experimental conditions given in Table 1, we have plotted the standard deviation of the fitted Gaussian curves, $\sigma$, as a function of "average" particle trajectory distance and have found that the relationship is linear, as shown in Fig. 5. Note the effect that the sweep gas velocity (compare I and II) has on the dispersion of the plume; as the sweep gas velocity is increased, we see that the dispersion of the plume decreases significantly.

\section{Conclusions \& Discussion}

We have examined the time-dependent statistical distributions of charged-particle swarms by using state-of-the-art flow and particle-visualization techniques. By assuming that the particle distributions are Gaussian and adopting a Lagrangian-like viewpoint, we have analyzed the "average" particle trajectory, $\mathbf{r}_{\mathrm{m}}$, and plume dispersion, as shown in Figs. 3-5.

Figure 6 illustrates the evolution of the swarm

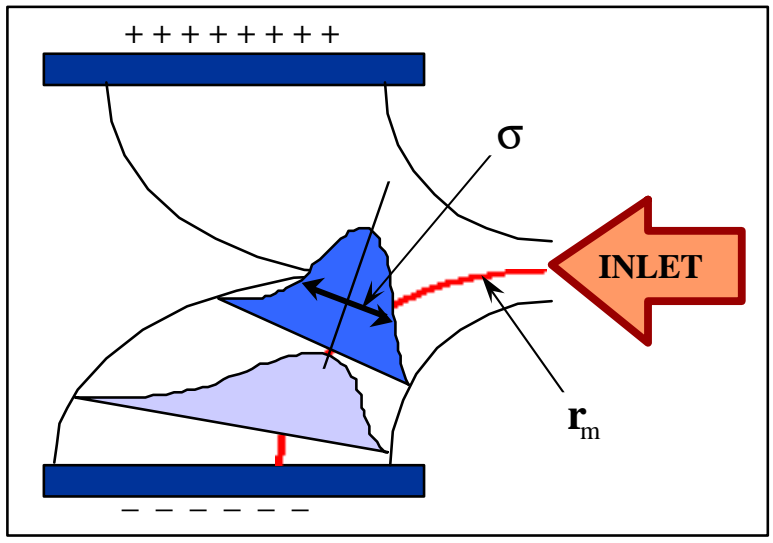

Figure 6. Illustration of "average" particle trajectory, $\mathbf{r}_{\mathrm{m}}$, and swarm dispersion, $\sigma$ density distribution. Qualitatively, $\mathbf{r}_{\mathrm{m}}$ is primarily influenced by the external electric field, whereas $\sigma$ is primarily affected by drag and interparticle electrostatic forces. The details of a theoretical development will be published elsewhere.

\section{References}

1. J. Lowell and A. C. Rose-Innes, Adv. Phys. 29, 947 (1980)

2. N. Hamamoto, Y. Nakajima, and T. Sato, J. Electrostatics 28, 161 (1992)

3. J. Lowell and A. Brown, J. Electrostatics 21, 69 (1988)

4. A. R. Akande and J. Lowell, J. Phys. D: Appl. Phys. 20, 565 (1987) 
5. H. W. Gibson, Polym. Rev. 25, 3 (1984)

6. R. A. Guistina, J. H. Anderson, and D. E. Bugner, J. Imaging Sci. and Tech. 37, 439 (1993)

7. C. B. Duke and T. J. Fabish, J. Appl. Phys. 49, 315 (1978)

8. J. H. Anderson, J. Imaging Sci. and Tech. 33, 200 (1989)

9. L. B. Schein, J. Imaging Sci. and Tech. 37, 1 (1993)

10. T. A. Edison, U. S. Patent \# 476,991; June 14, 1892

11. R. Ciccu, R. Peretti, A. Serci, M. Tamanini, and A. Zucca, J. Electrostatics 23, 157 (1989)

12. C. W. Bouchillon and W. G. Steele, Particulate Sci. and Tech. 10, 73 (1992)

13. R. Gupta, D. Gidaspow, and D. T. Wasan, Powder Tech. 75, 79 (1993)

14. K. Schonert, K. Eichas, and F. Niermoller, Powder Tech. 86, 41 (1996)

15. J. Doney, Ph.D. Thesis, Carnegie Mellon University, Pittsburgh, PA (1996)

16. J. Doney, D. Finseth, J. Sinclair, and F. Shaffer, ASME-FED 228, 393 (1995)

17. M. S.Jhon, G. Sekhon, and R. Armstrong, Adv. Chem. Phys., 66, 153 (1987).

18. R. Gupta, Ph.D. Thesis, Illinois Institute of Technology, Chicago, IL (1990) 
Appendix

\section{A Study of}

\section{Multi-Particle Dynamics in}

\section{Triboelectrostatic Systems}

Department of Chemical Engineering, Carnegie Mellon University:

- Stephen J. Vinay III (speaker); Myung S. Jhon, Professor; Charles M. Schroeder III

Solid Fuels Division, Federal Energy Technology Center:

- Richard Schehl; Yee Soong; McMahan Gray; Dennis Finseth; Bill Sands 


\section{Outline}

$>$ Essence of the Problem \& Application

$>$ Experimental

$»$ A History of Triboelectrostatic Separations

»Particle Flow Analysis Facility (PFAF)

»Results from the PFAF -- Experimental Results \& Animation of Particle Trajectories

$>$ Theoretical

»Probability Density Function Approach -- Qualitative

Data Interpretation

»Concentration Equation

»Moment Analysis \& Illustration 


\section{Essence of the Problem}

$>$ Single Particle: Particle/Fluid Coupling

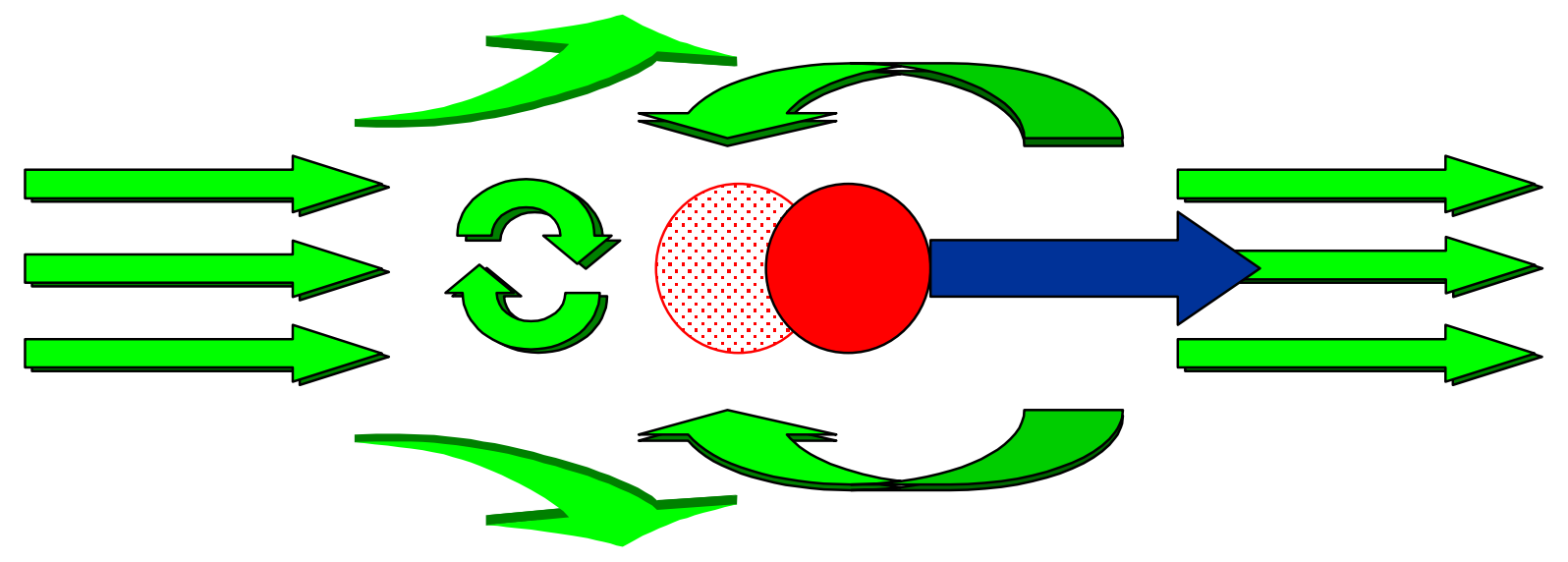

$>$ Particle "Swarms": Interparticle Interactions

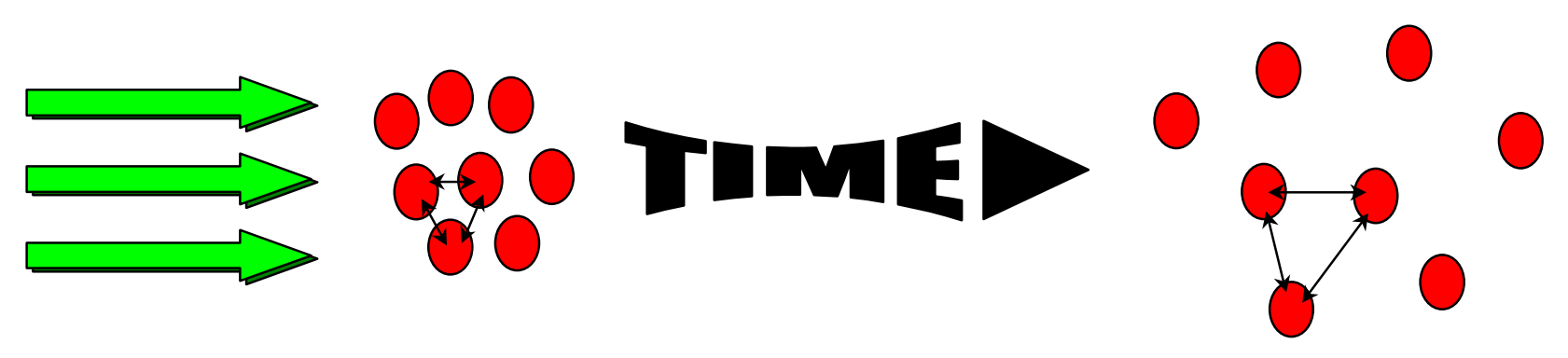




\section{Energy/Environmental Application}

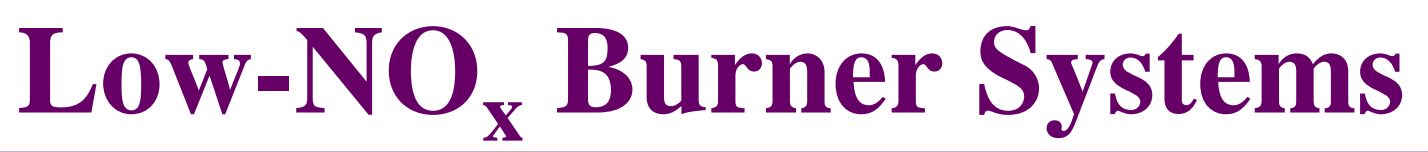

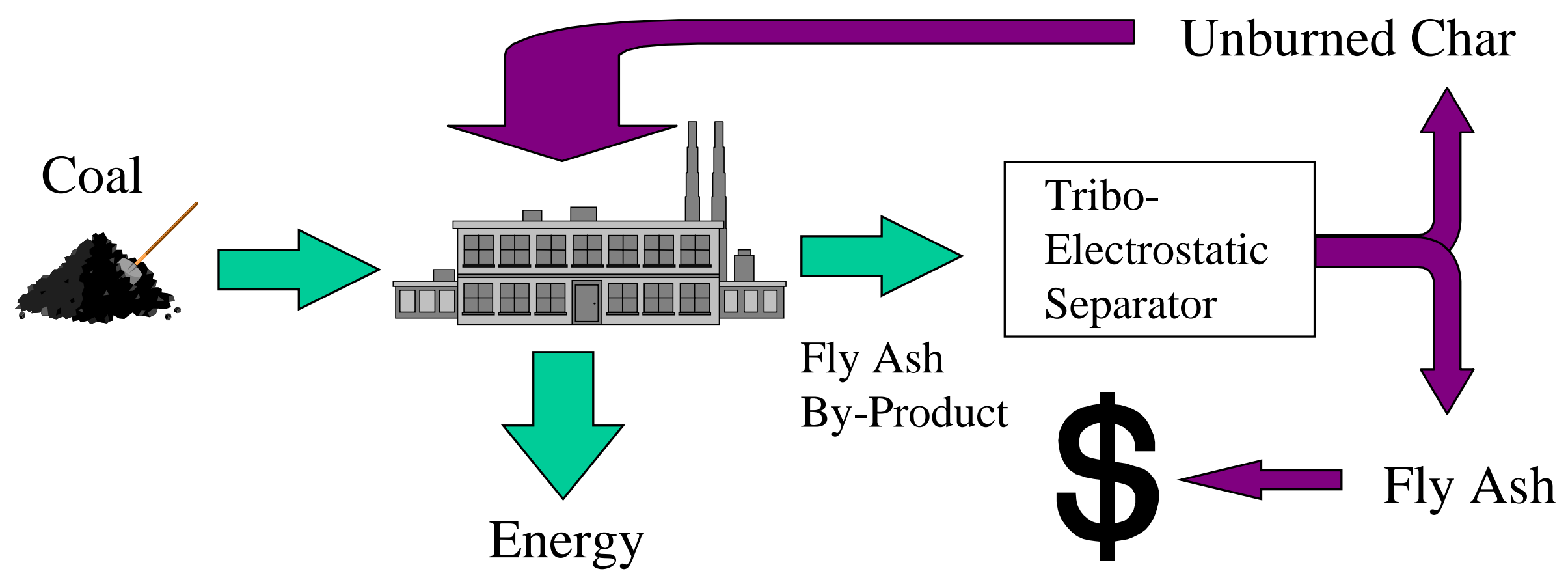




\section{Other Triboelectrostatic Applications}

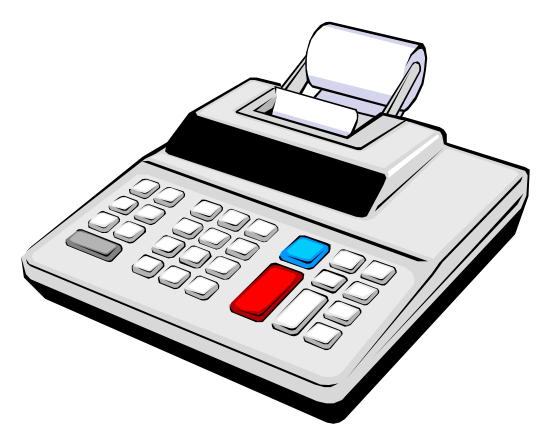

Electronic Scrap/ Recovery of Precious Metals

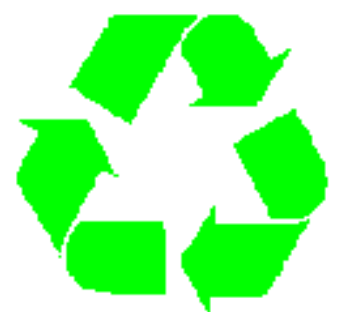

Polyethylene Bottle Recycling

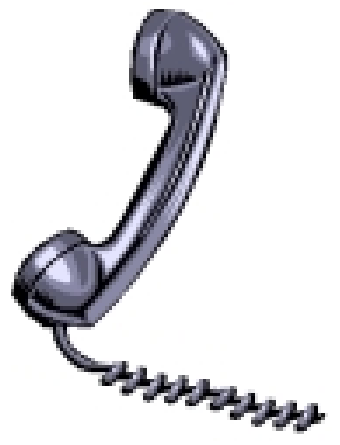

Chopped Wire Processing

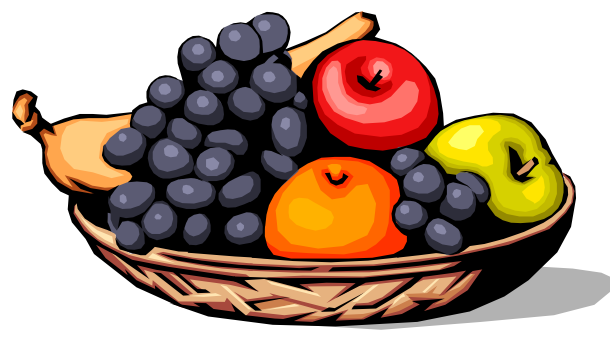

Food

Processing/ Purification

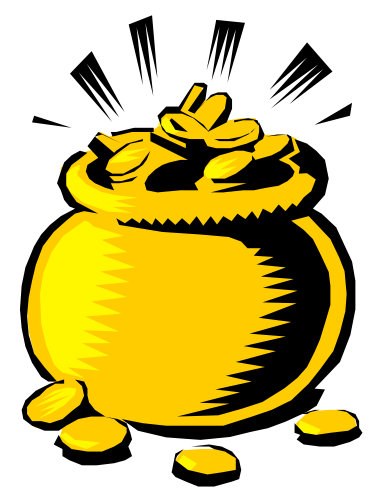

Recovery of Precious Metals from Slags

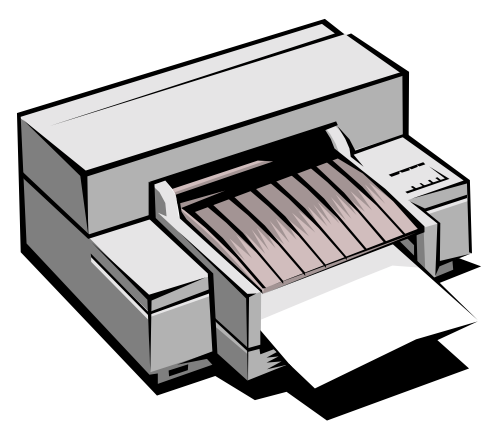

Electrophotography/ Graphics 


\section{Outline}

$>$ Essence of the Problem \& Application

$>$ Experimental

$»$ A History of Triboelectrostatic Separations

»Particle Flow Analysis Facility (PFAF)

»Results from the PFAF -- Experimental Results \& Animation of Particle Trajectories

$>$ Theoretical

»Probability Density Function Approach -- Qualitative

Data Interpretation

»Concentration Equation

»Moment Analysis \& Illustration 


\section{Thomas Edison's Pioneering Work (June 14, 1892)}

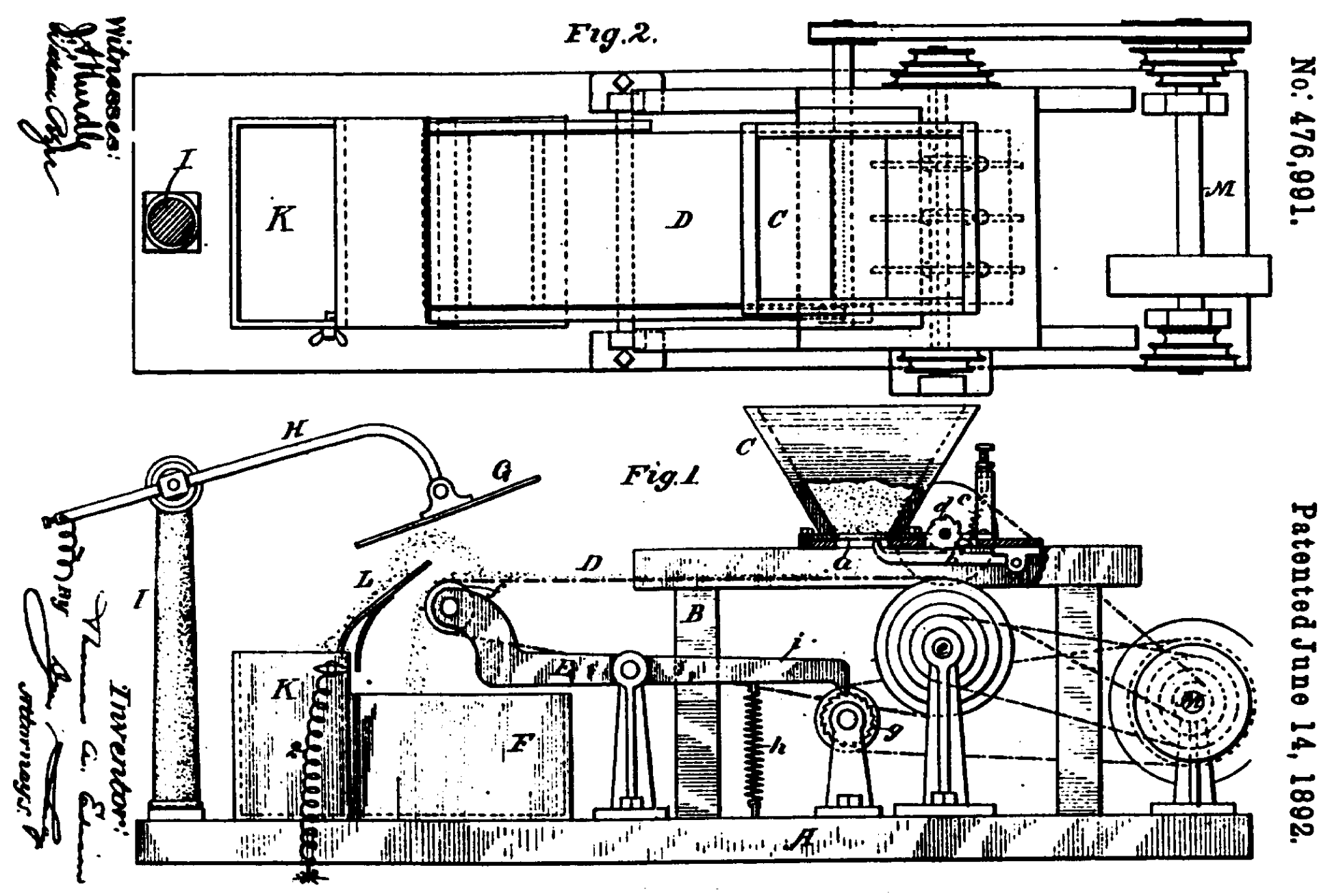




\section{One Century Later...}

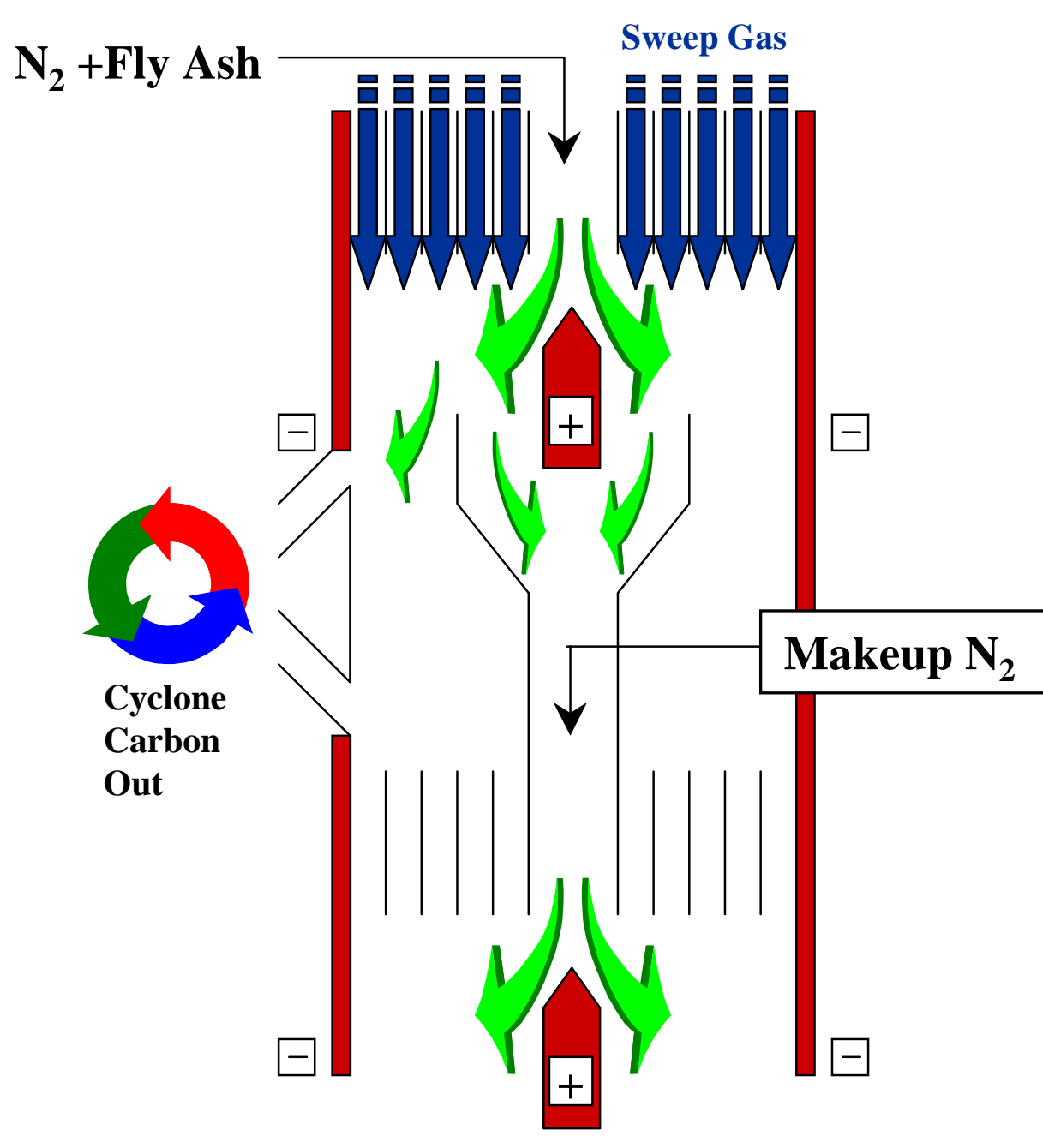

FETC's Prototype

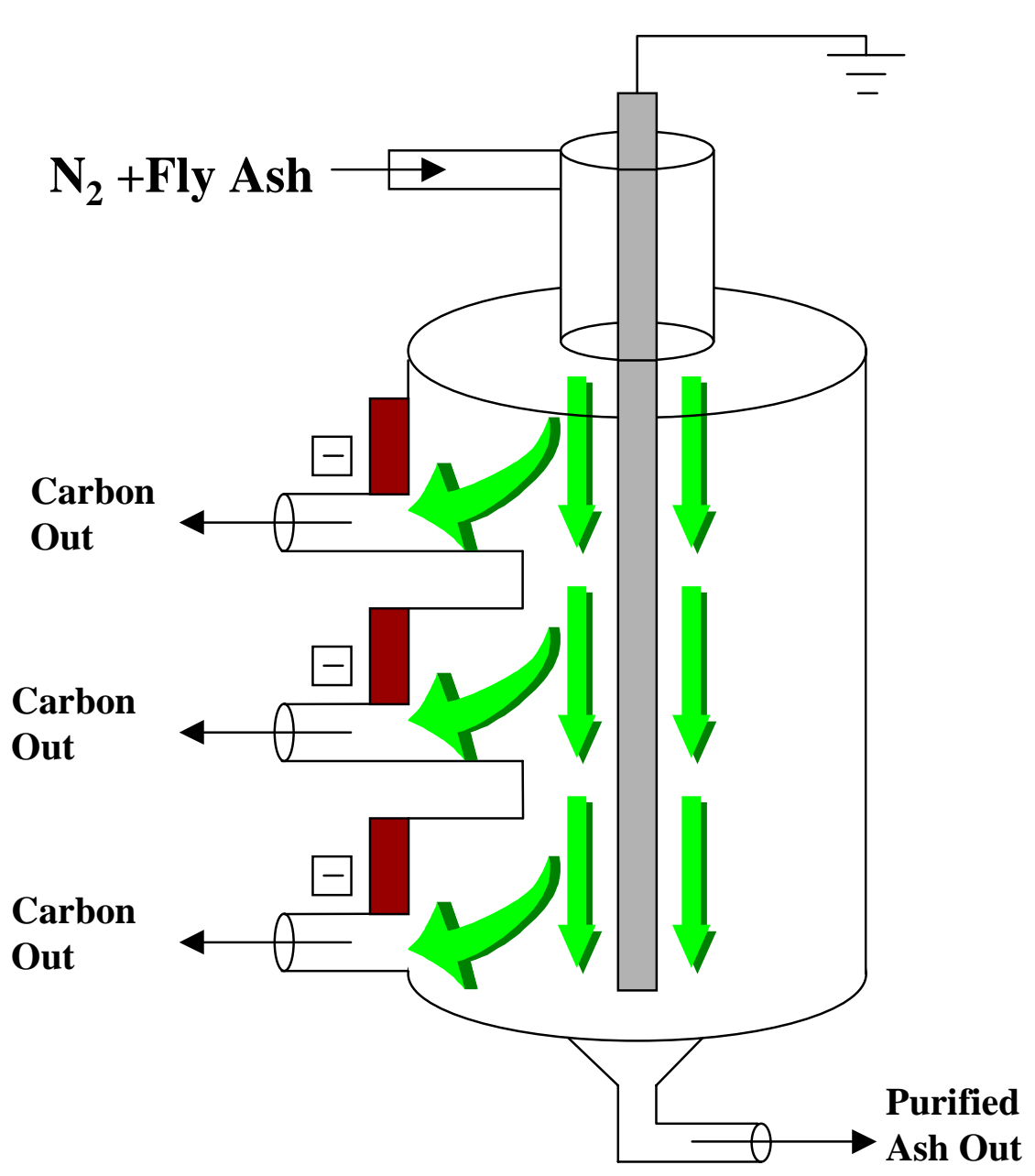

Ban \& Stencel; U. of Kentucky 


\section{Particle Flow Analysis Facility (PFAF)}

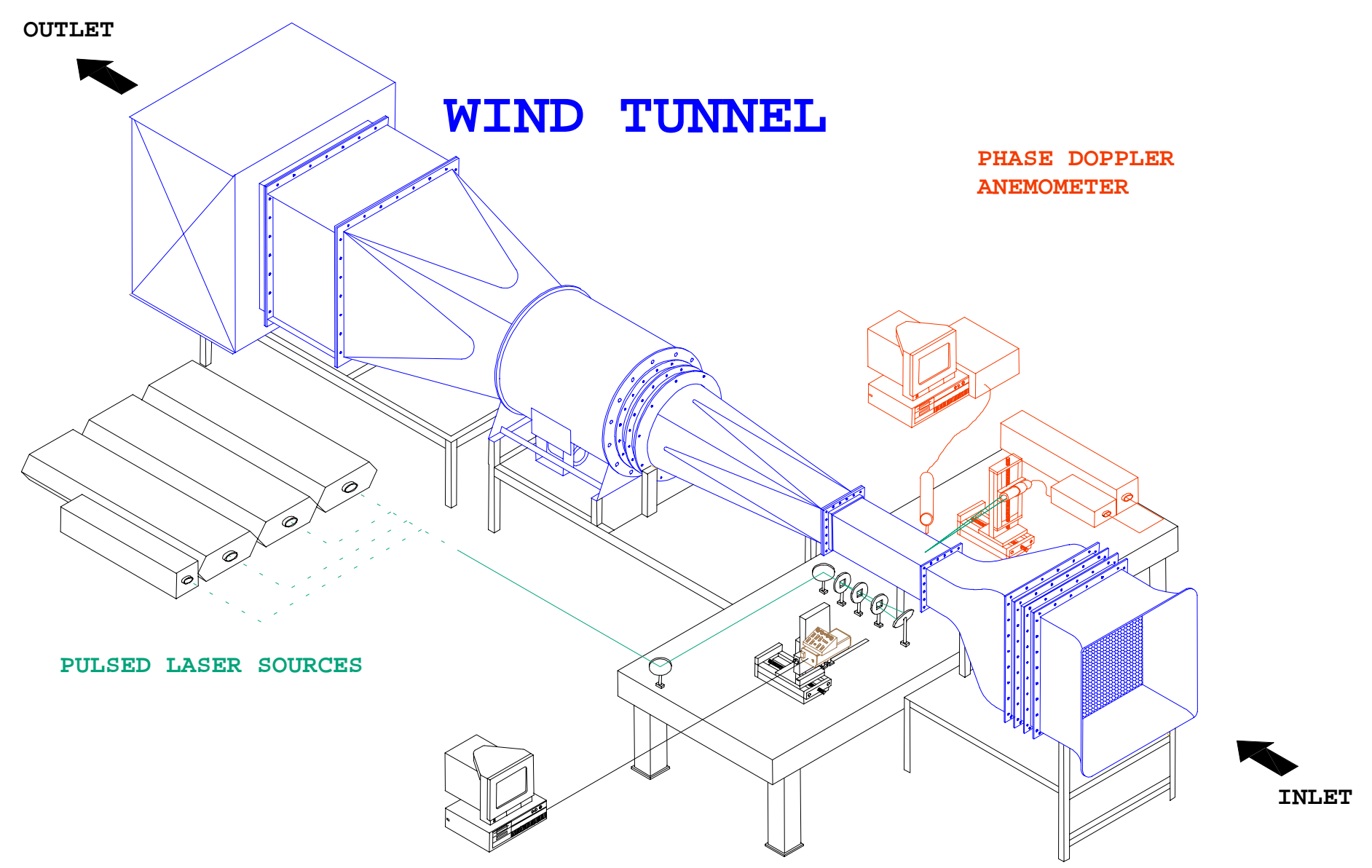




\section{Flow Visualization Components}

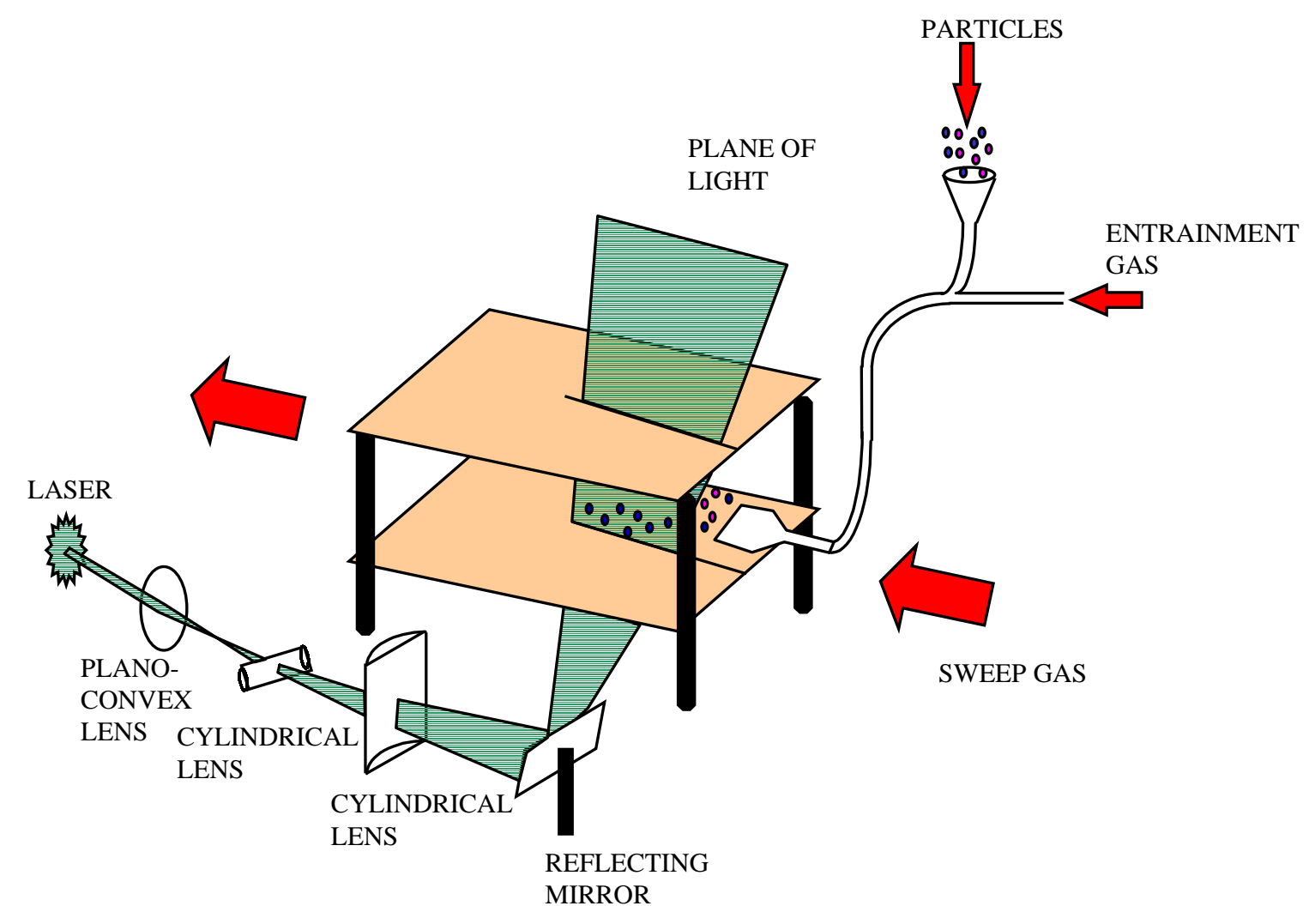

\section{-Data Acquisition System -Laser Doppler Velocimetry System}




\section{Typical PFAF Tribo Data}
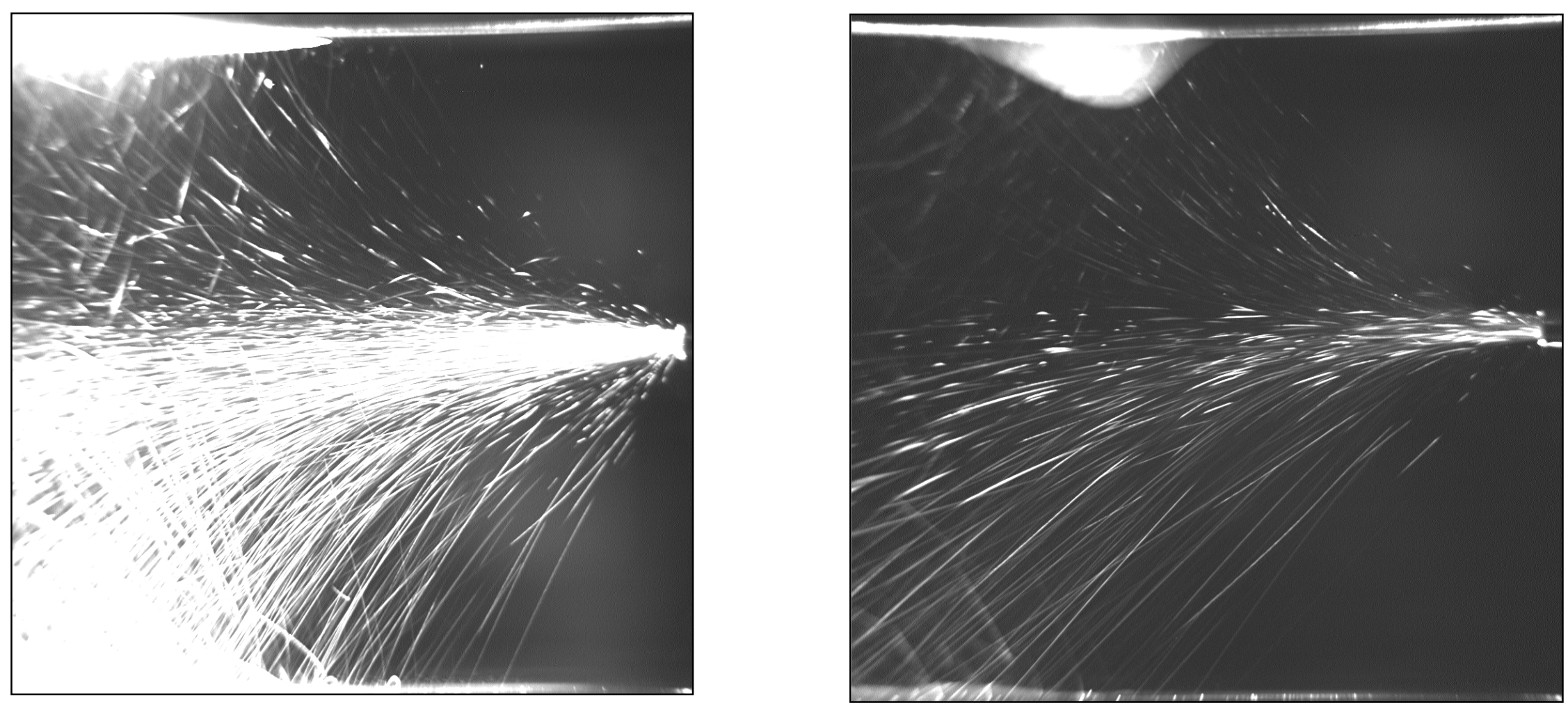


\section{Particle "Swarm" Dynamics (Qualitative Picture)}

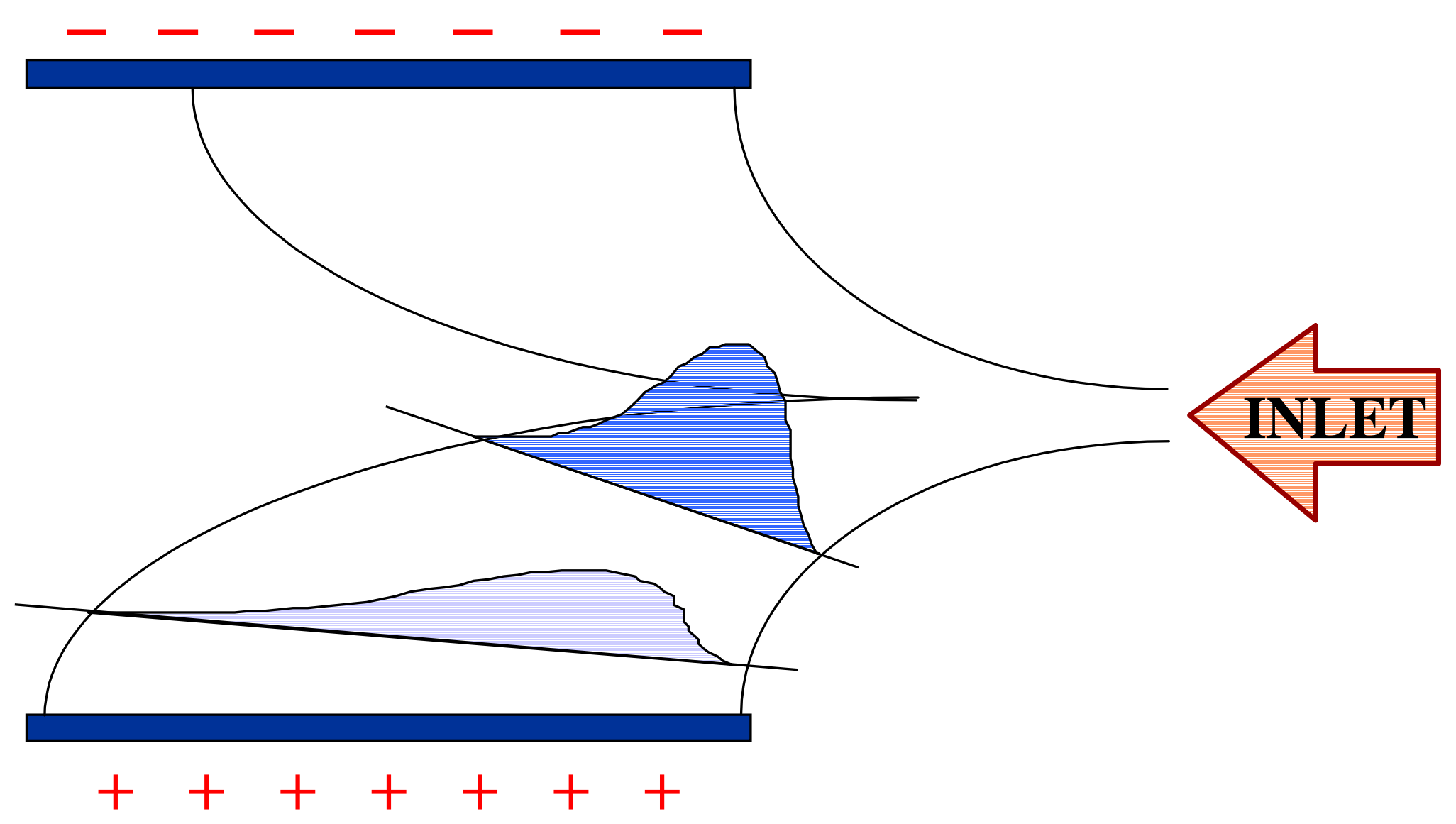




\section{Image Analysis}

$>$ For N "pictures":

$»$ Pixel-by-pixel addition of intensity

»Division by $\mathbf{N}$

»Subtraction of background

$>$ "Raw" Averaged Image:

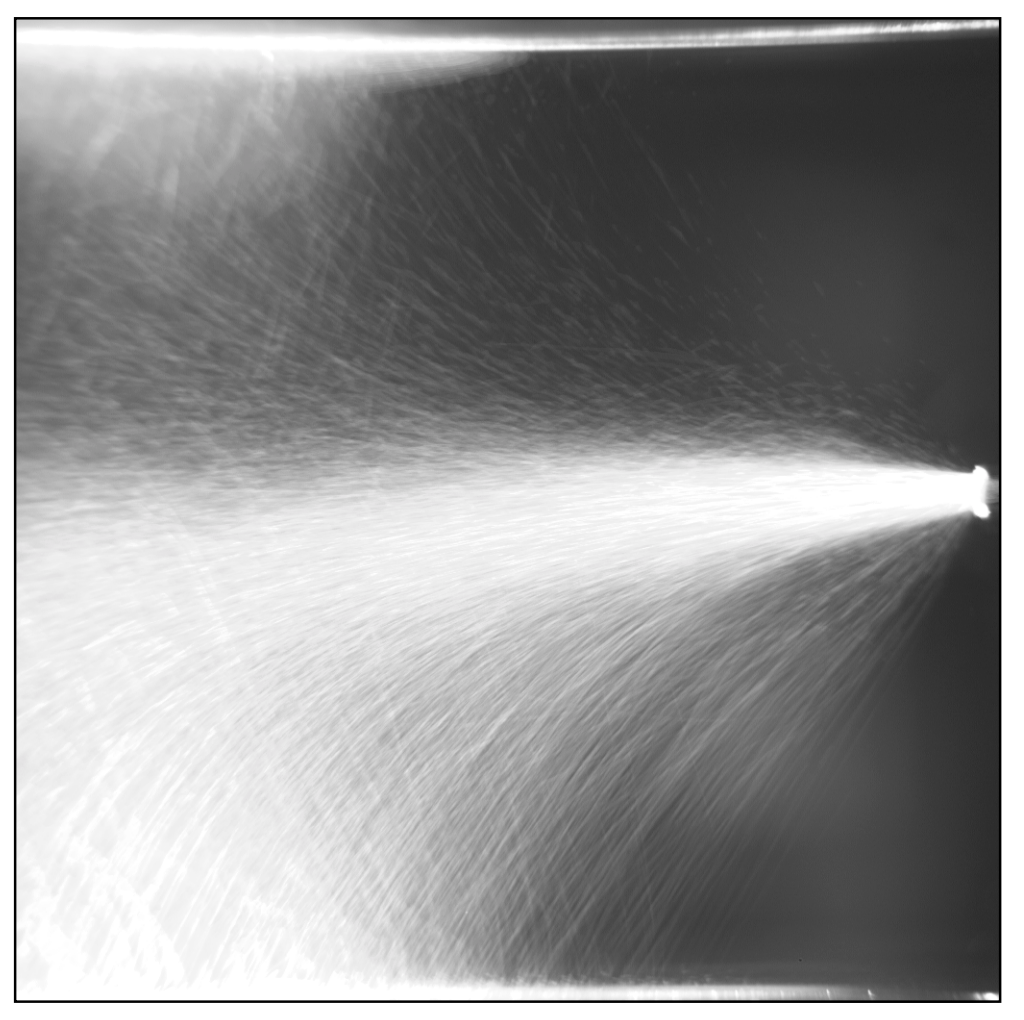




\section{Controlled Experiments}

\section{Effect of Drag Force}

Wind Tunnel: $\quad \mathbf{1 . 0 5 8} \mathrm{m} / \mathrm{s}$

$\mathrm{N}_{2}$ Flowmeter: $2.694 \mathrm{~m} / \mathrm{s}$

Electric Field: $\quad+/-2.5 \cdot 10^{4} \mathrm{~V}$

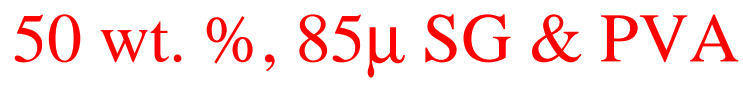

Wind Tunnel: $2.739 \mathrm{~m} / \mathrm{s}$

$\mathrm{N}_{2}$ Flowmeter: $\quad 2.694 \mathrm{~m} / \mathrm{s}$ Electric Field: $\quad+/-2.5 \cdot 10^{4} \mathrm{~V}$ 50 wt. $\%, 85 \mu$ SG \& PVA

(1)

(2)

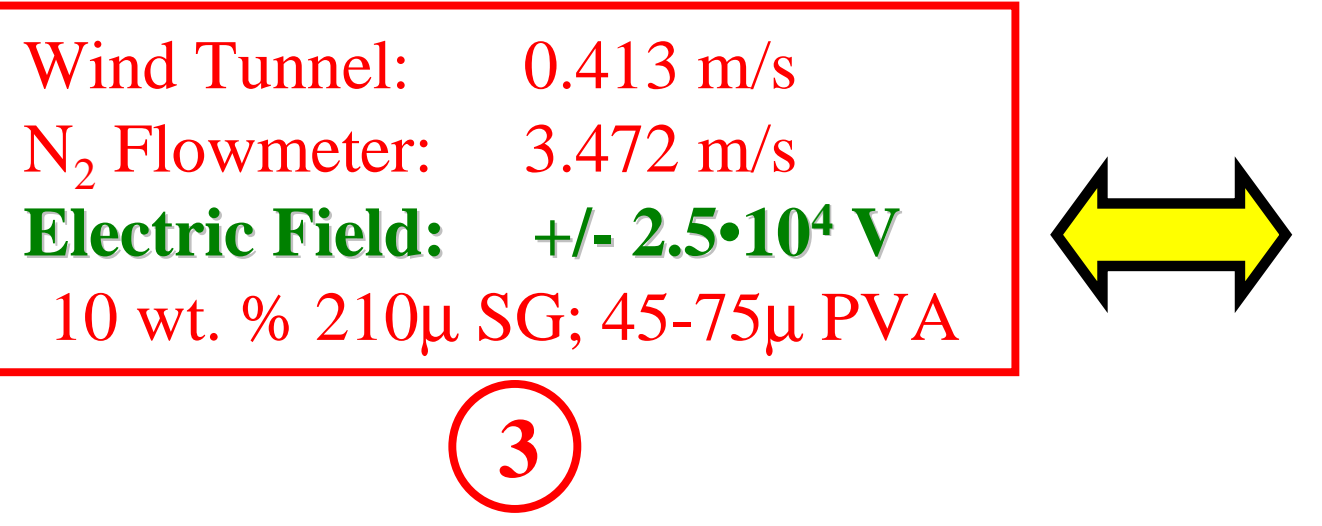

Wind Tunnel: $\quad 0.413 \mathrm{~m} / \mathrm{s}$

$\mathrm{N}_{2}$ Flowmeter: $\quad 3.472 \mathrm{~m} / \mathrm{s}$

Electric Field: $\quad 0$ V

10 wt. $\% 210 \mu$ SG; $45-75 \mu$ PVA

(4)

SG $\rightarrow$ Silica Gel; PVA $\rightarrow$ Polyvinyl Alcohol 


\section{1}

\section{Wind Tunnel: $1.058 \mathrm{~m} / \mathrm{s}$}

$\mathrm{N}_{2}$ Flowmeter: $2.694 \mathrm{~m} / \mathrm{s}$

Electric Field: $\quad+/-2.5 \cdot 10^{4} \mathrm{~V}$

50 wt. $\%, 85 \mu$ SG \& PVA 
(1)

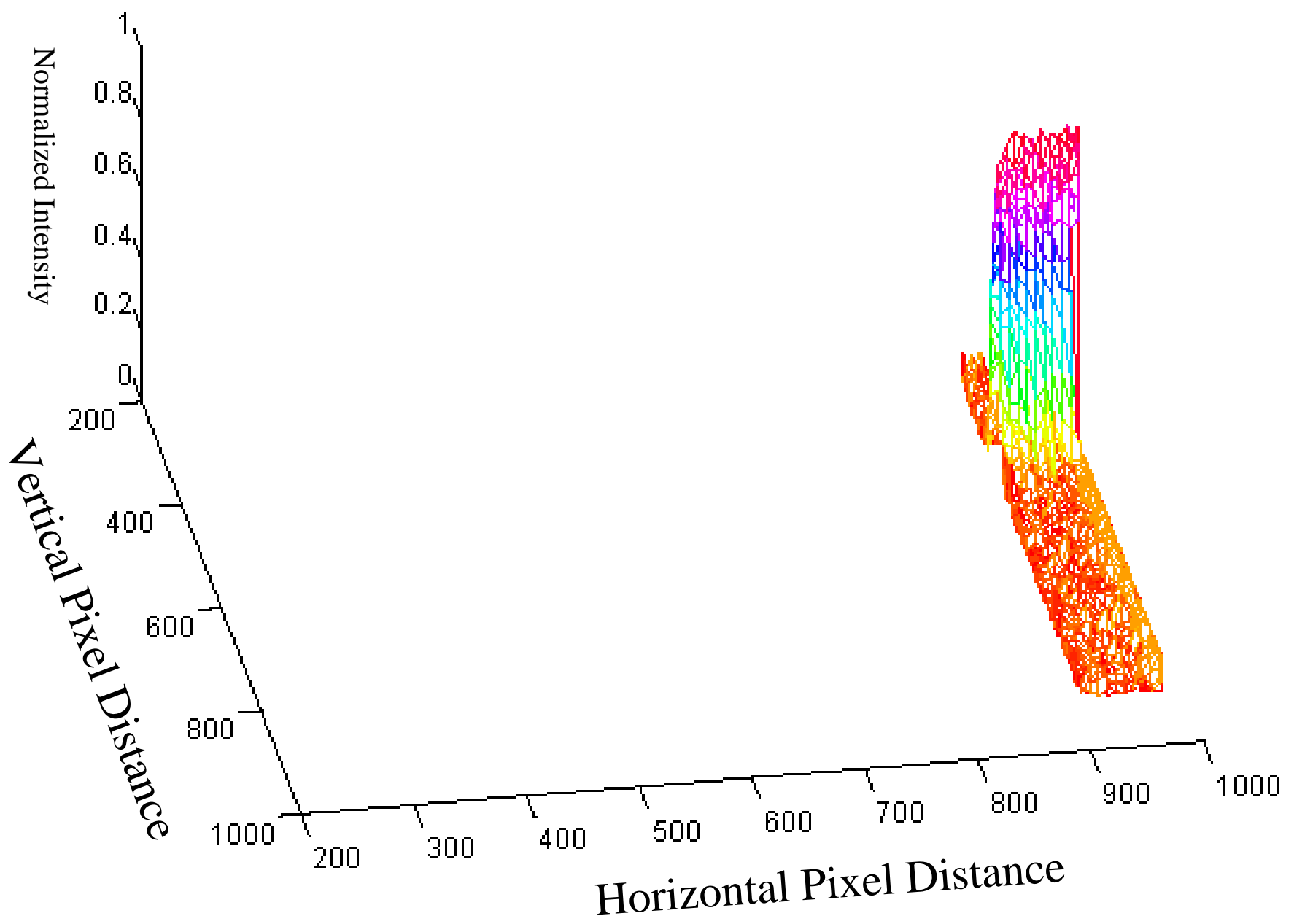


(1)

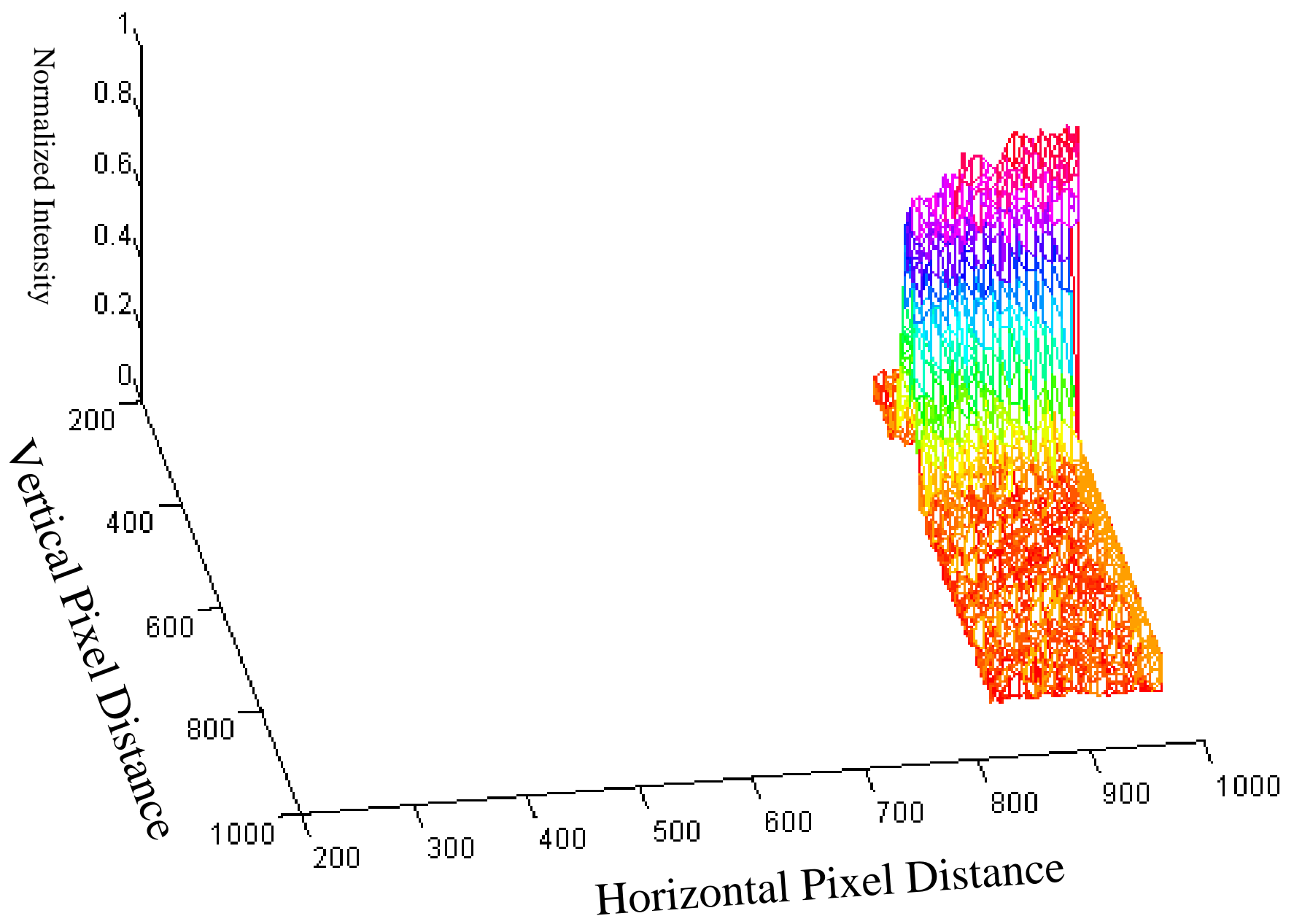


(1)

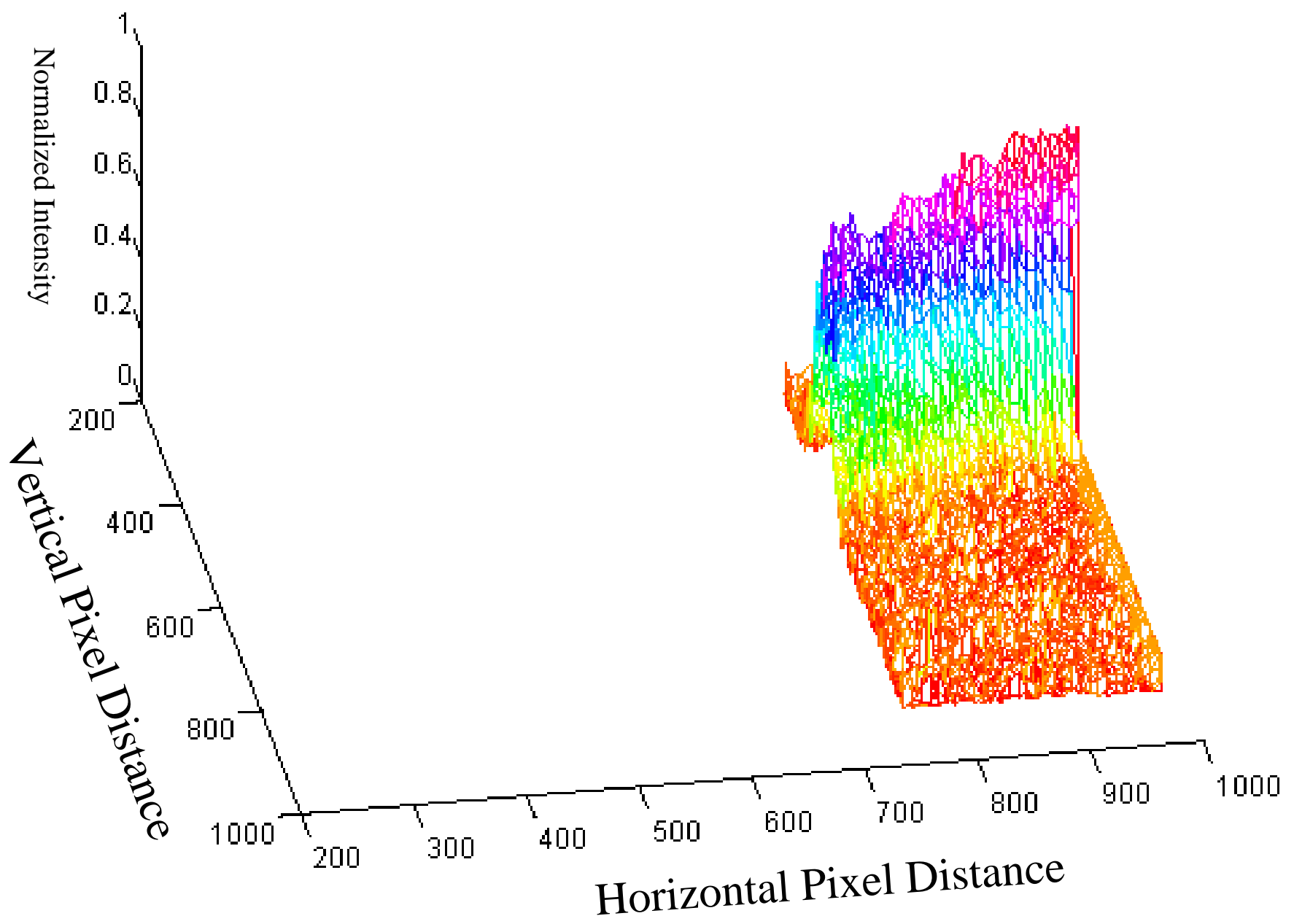


(1)

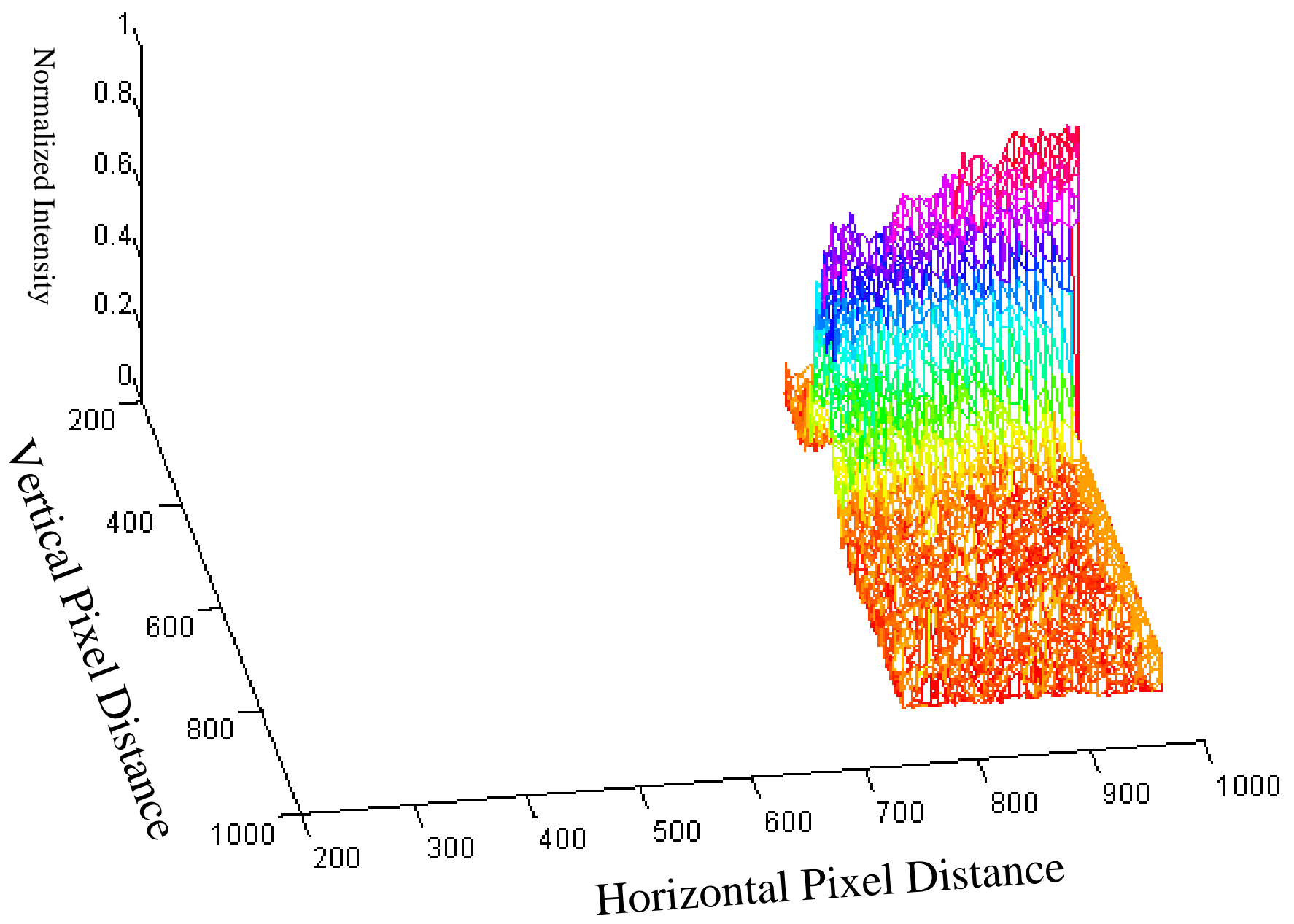




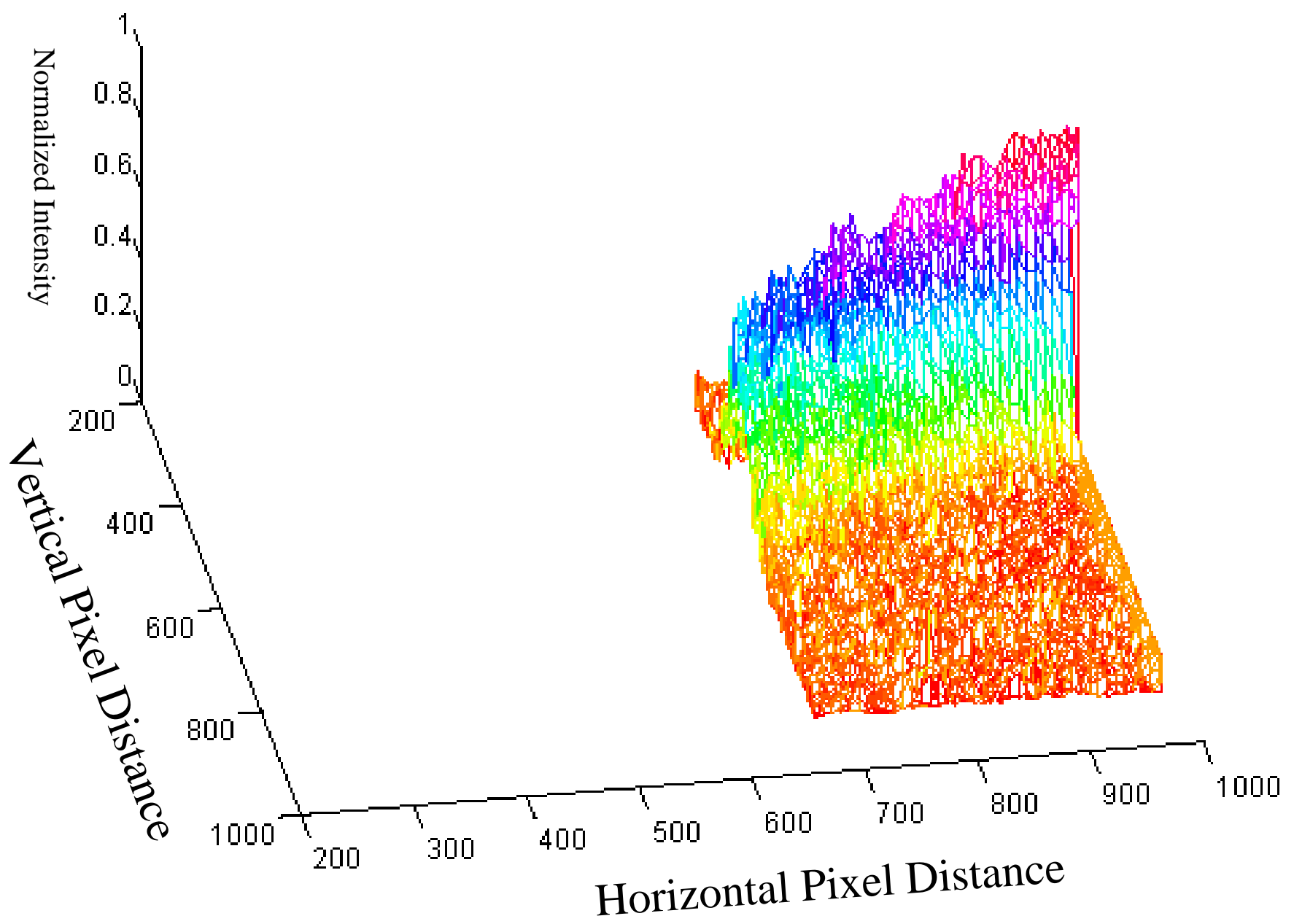




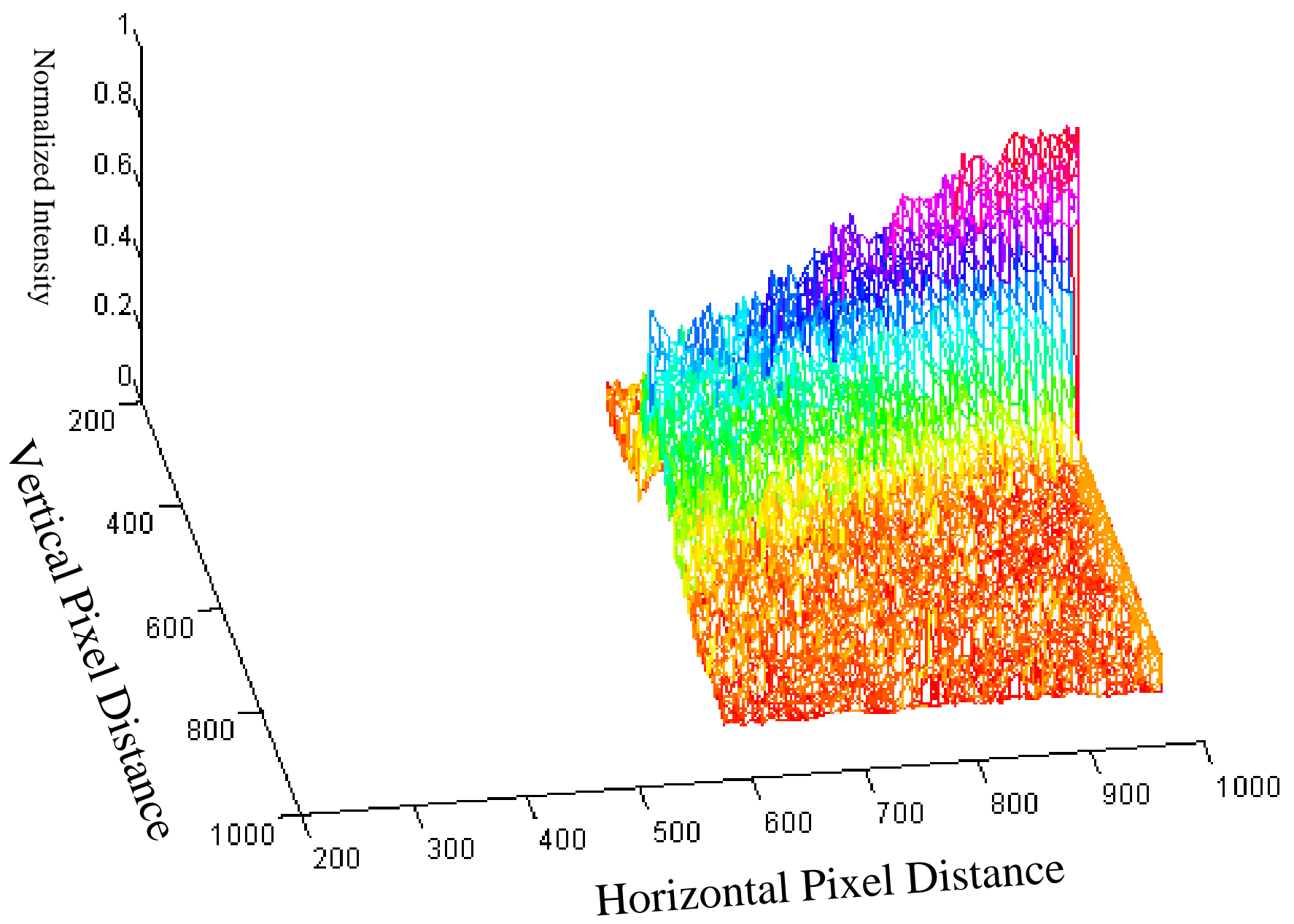




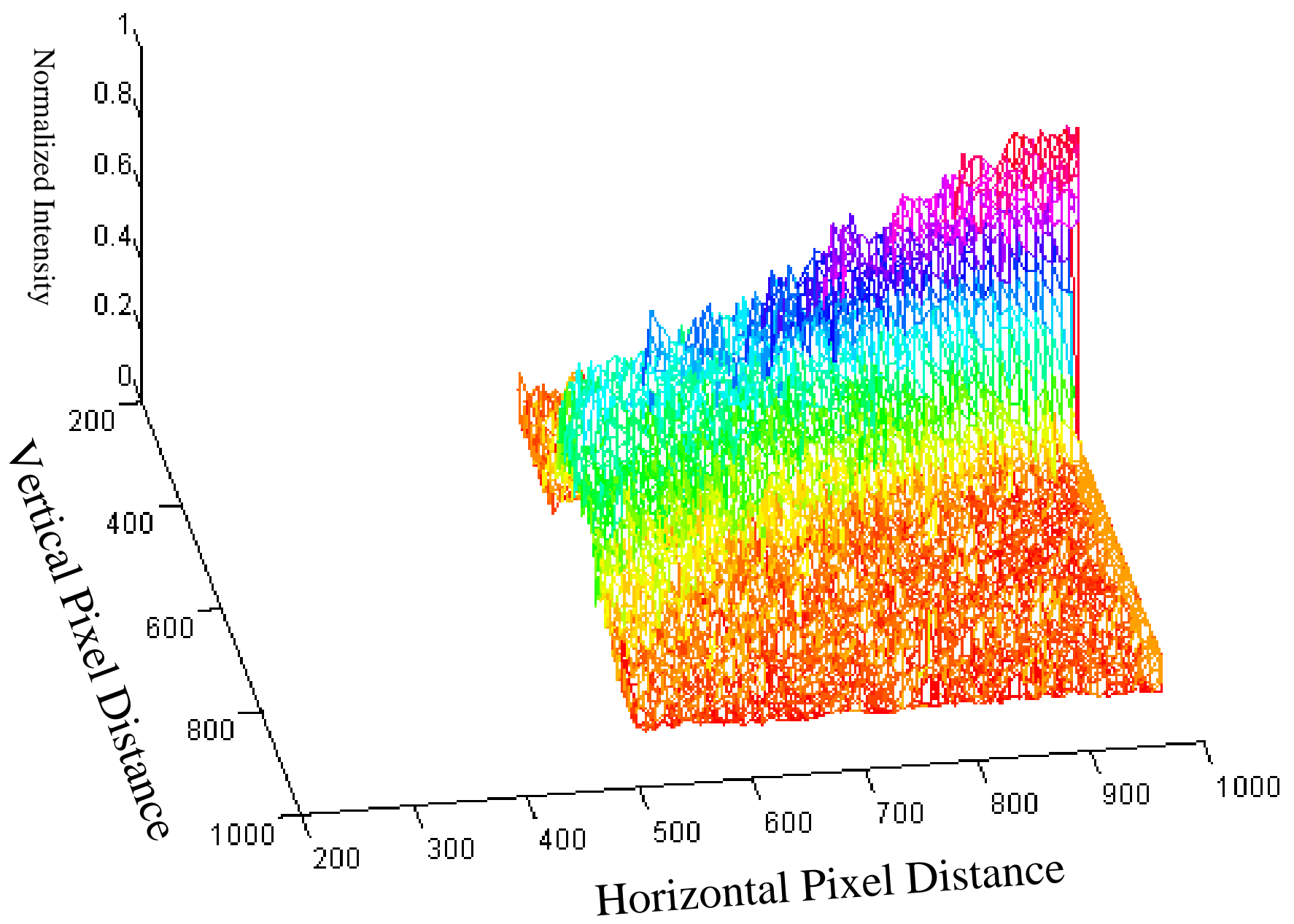




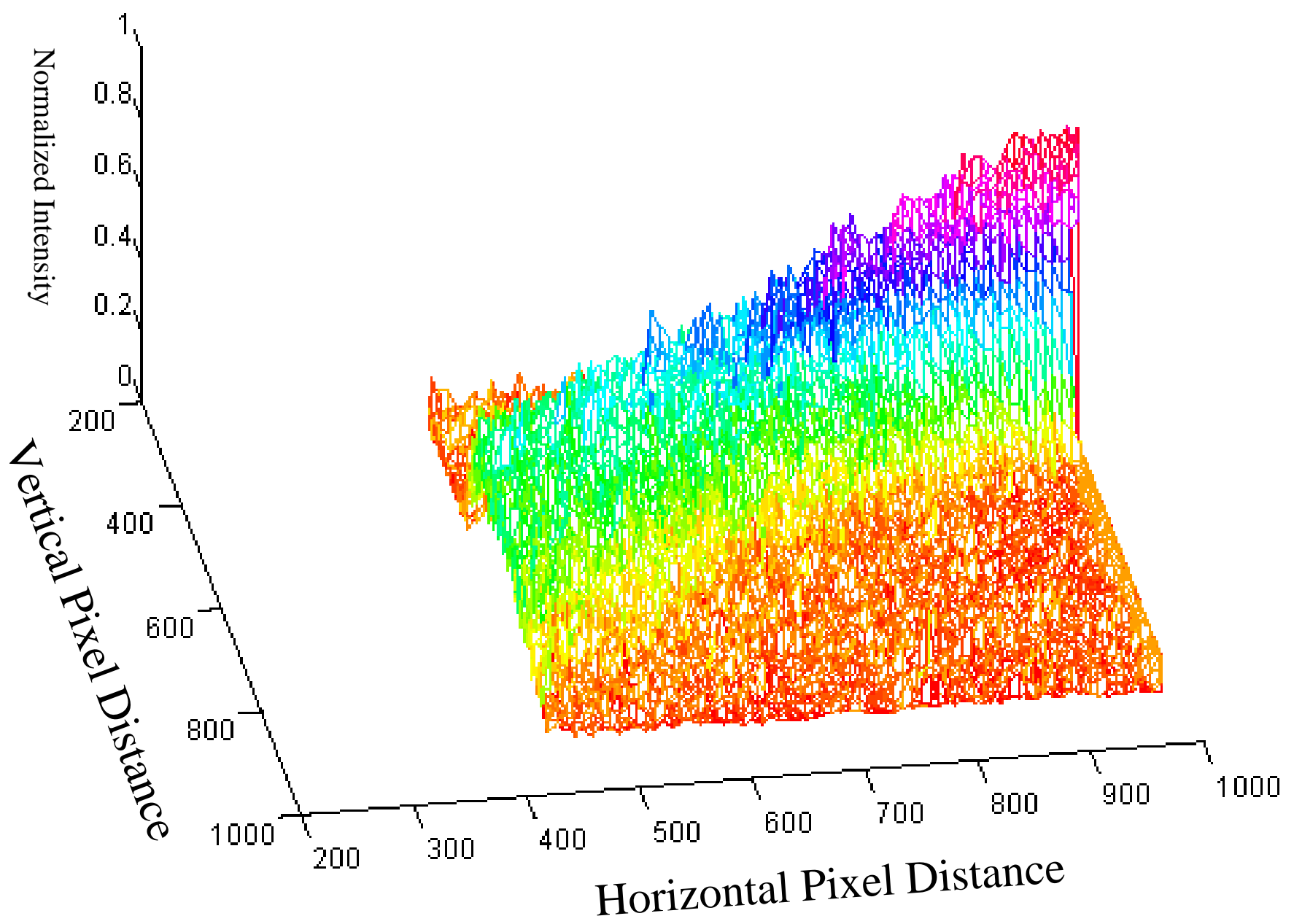




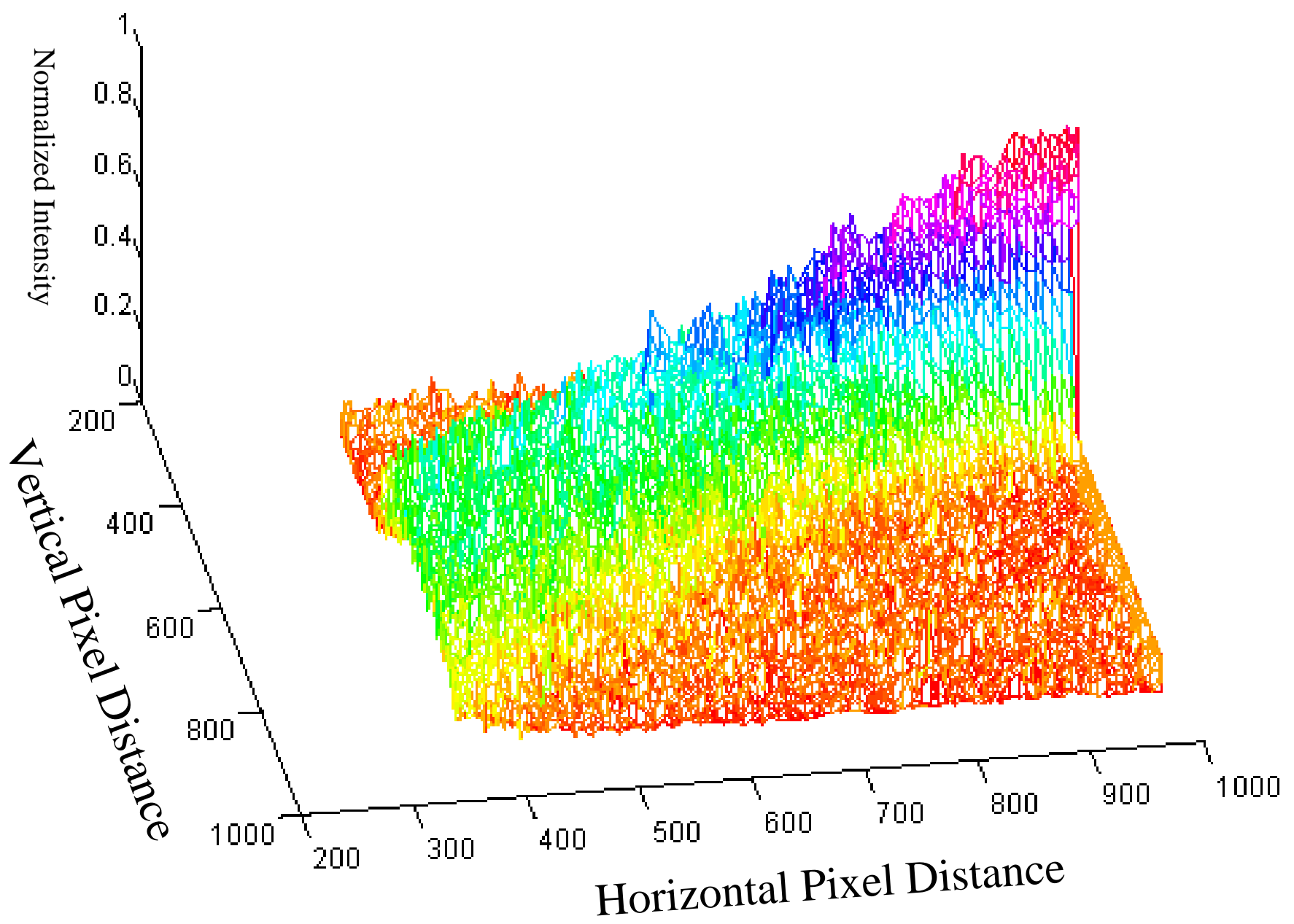




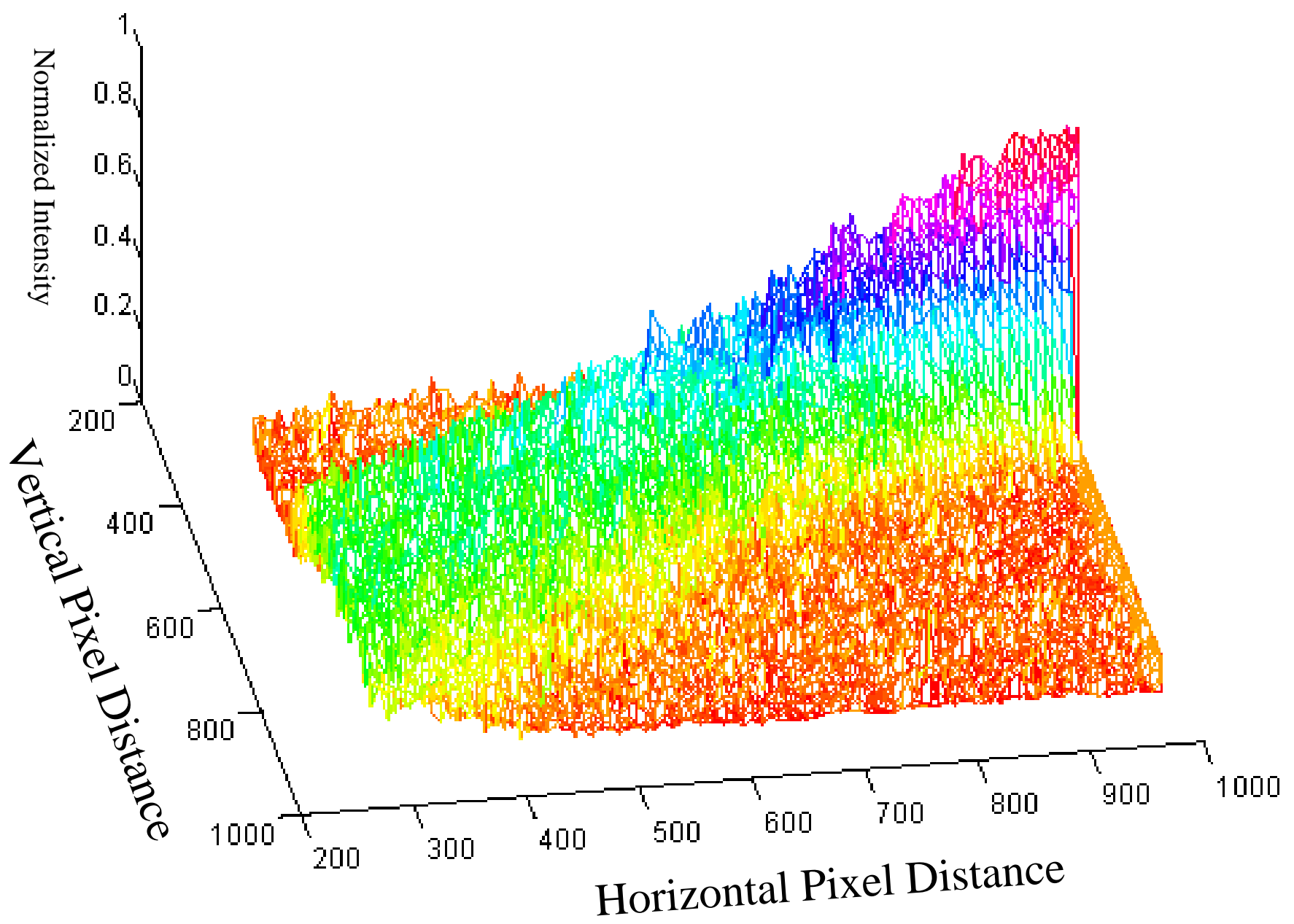




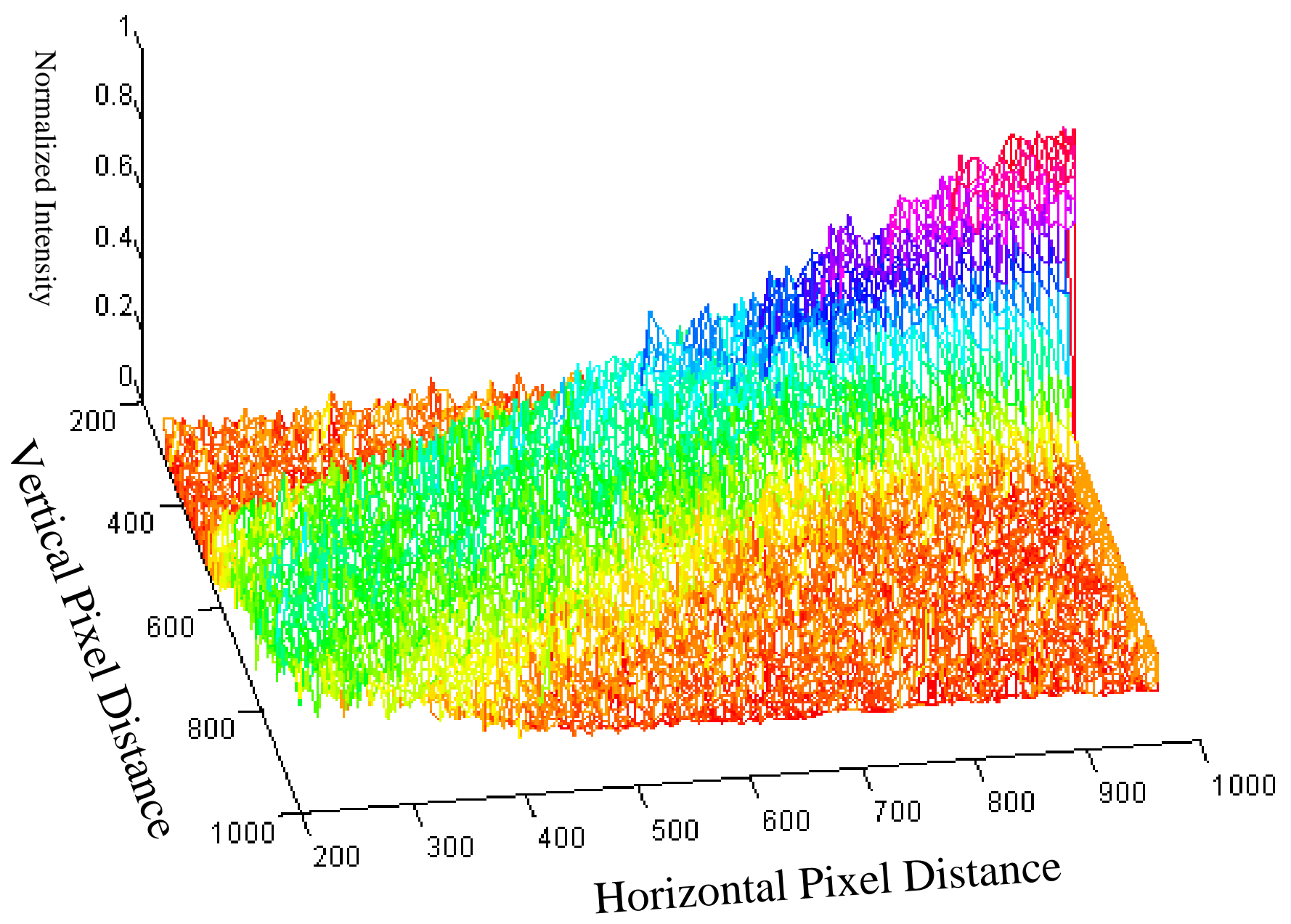


Wind Tunnel: $\quad 1.058 \mathrm{~m} / \mathrm{s}$

$\mathrm{N}_{2}$ Flowmeter: $2.694 \mathrm{~m} / \mathrm{s}$

Electric Field: $\quad+/-2.5 \cdot 10^{4} \mathrm{~V}$ 50 wt. $\%, 85 \mu$ SG \& PVA

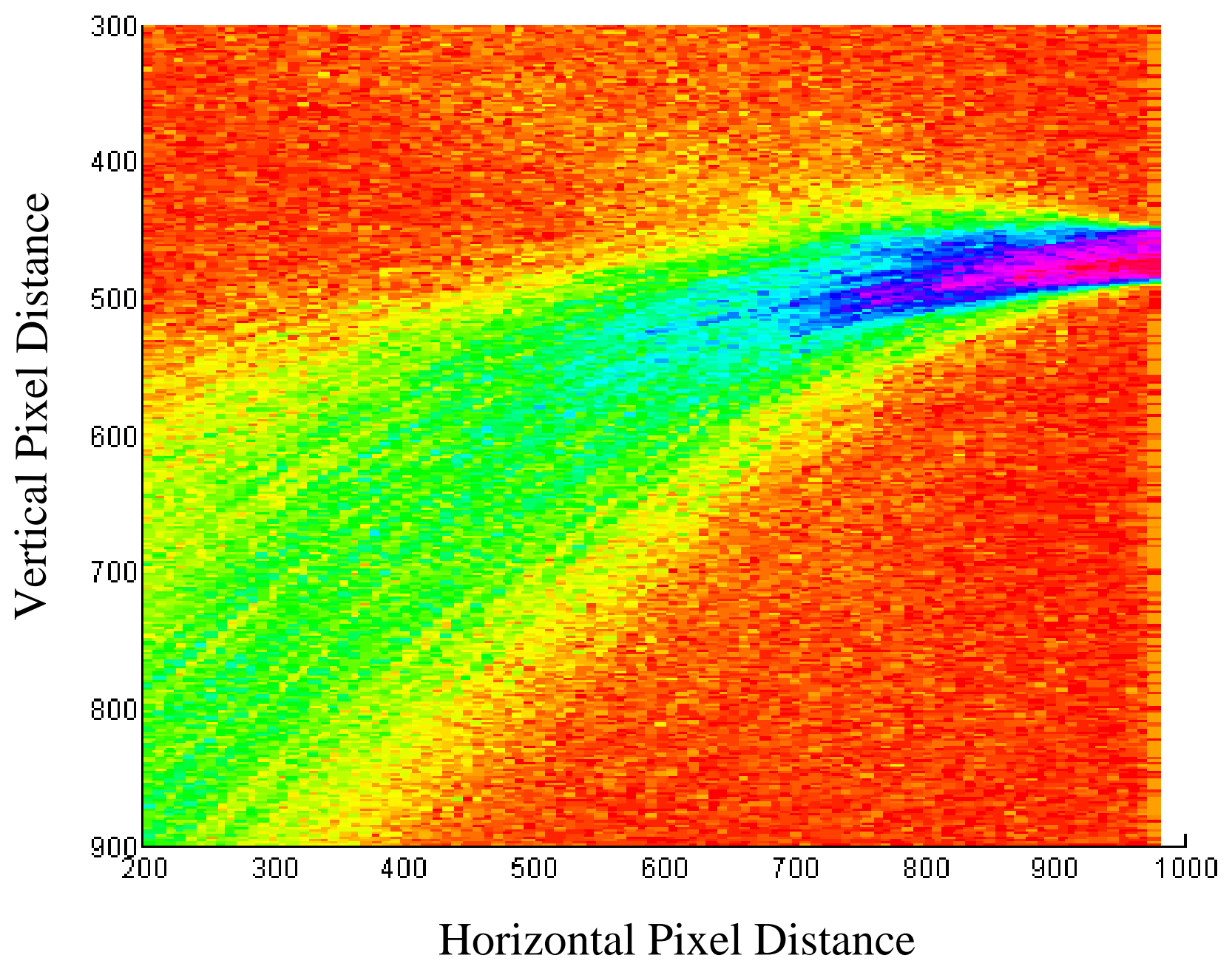




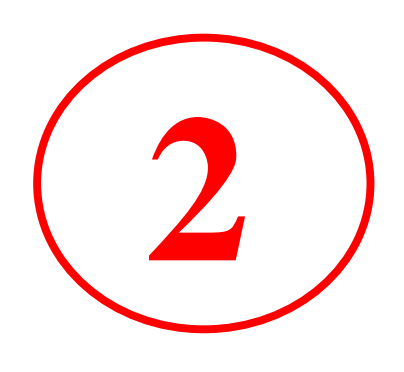

\section{Wind Tunnel: $2.739 \mathrm{~m} / \mathrm{s}$}

$\mathrm{N}_{2}$ Flowmeter: $2.694 \mathrm{~m} / \mathrm{s}$

Electric Field: $\quad+/-2.5 \cdot 10^{4} \mathrm{~V}$

50 wt. $\%, 85 \mu$ SG \& PVA 
(2)

Wind Tunnel: $\quad 2.739 \mathrm{~m} / \mathrm{s}$

$\mathrm{N}_{2}$ Flowmeter: $2.694 \mathrm{~m} / \mathrm{s}$

Electric Field: $\quad+/-2.5 \cdot 10^{4} \mathrm{~V}$ 50 wt. $\%, 85 \mu$ SG \& PVA

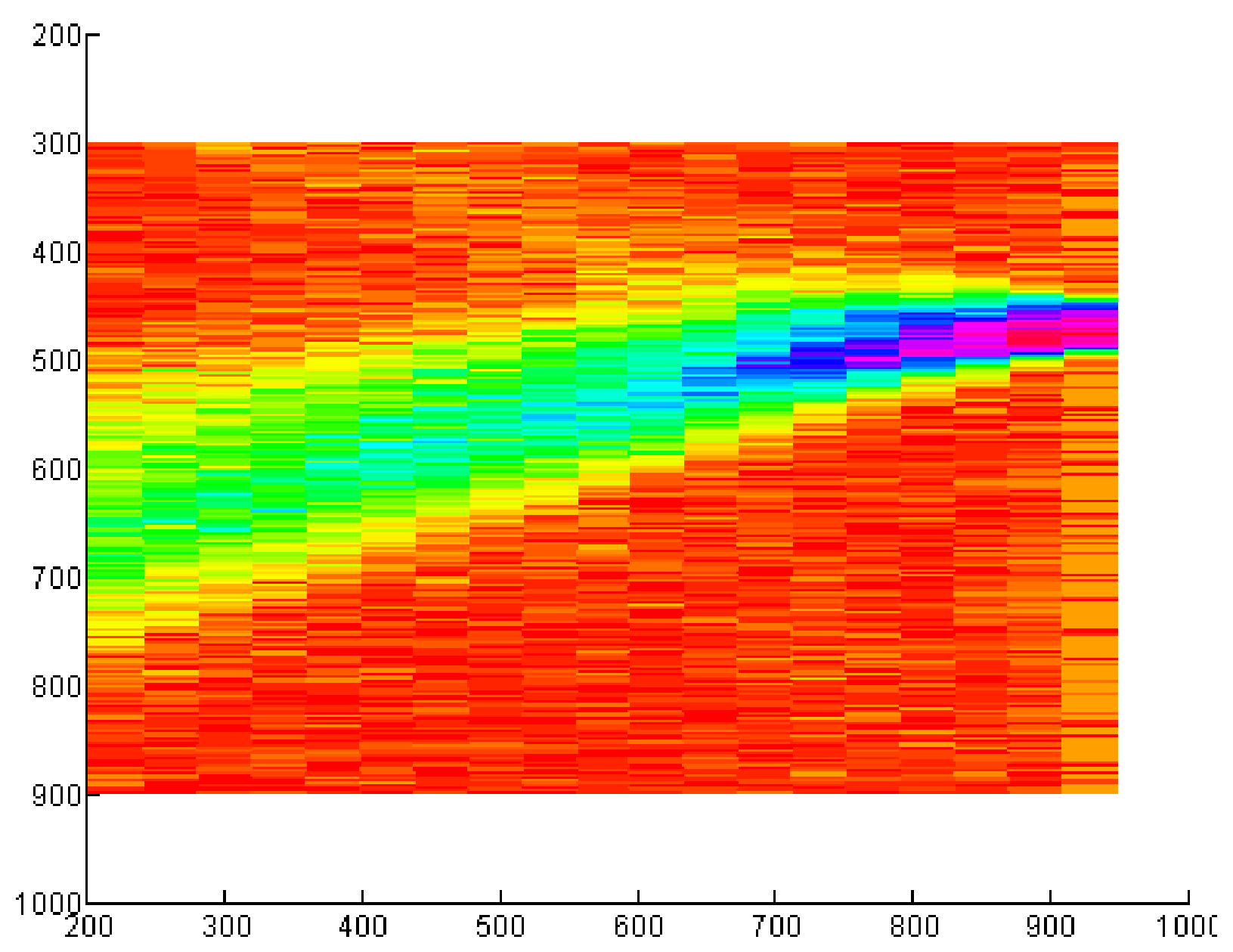




\section{Effect of Drag Force (Note that $\dot{r}_{\mathrm{i}} \approx \mathrm{v}\left(\mathrm{r}_{\mathrm{i}}\right)$ in (2))}

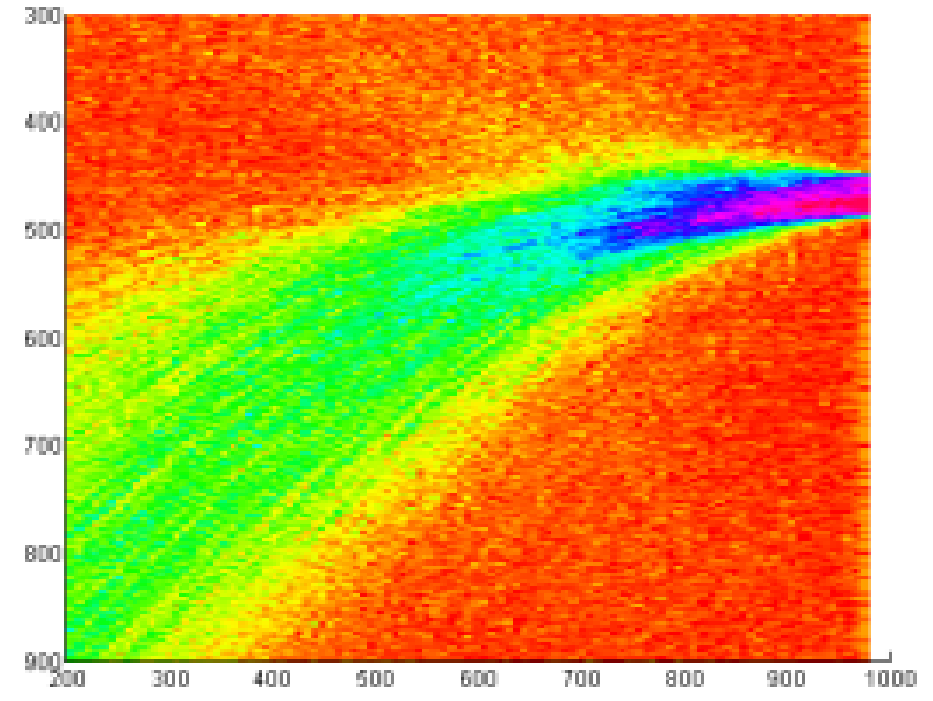

Wind Tunnel: $\quad 2.739 \mathrm{~m} / \mathrm{s}$

$\mathrm{N}_{2}$ Flowmeter: $\quad 2.694 \mathrm{~m} / \mathrm{s}$

Electric Field: $\quad+/-2.5 \cdot 10^{4} \mathrm{~V}$ 50 wt. $\%, 85 \mu$ SG \& PVA
(1)

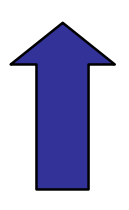

\section{Wind Tunnel: $\quad 1.058 \mathrm{~m} / \mathrm{s}$}

$\mathrm{N}_{2}$ Flowmeter: $2.694 \mathrm{~m} / \mathrm{s}$

Electric Field: $\quad+/-2.5 \cdot 10^{4} \mathrm{~V}$

50 wt. $\%, 85 \mu$ SG \& PVA

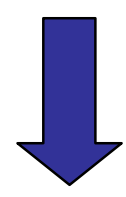

(2)

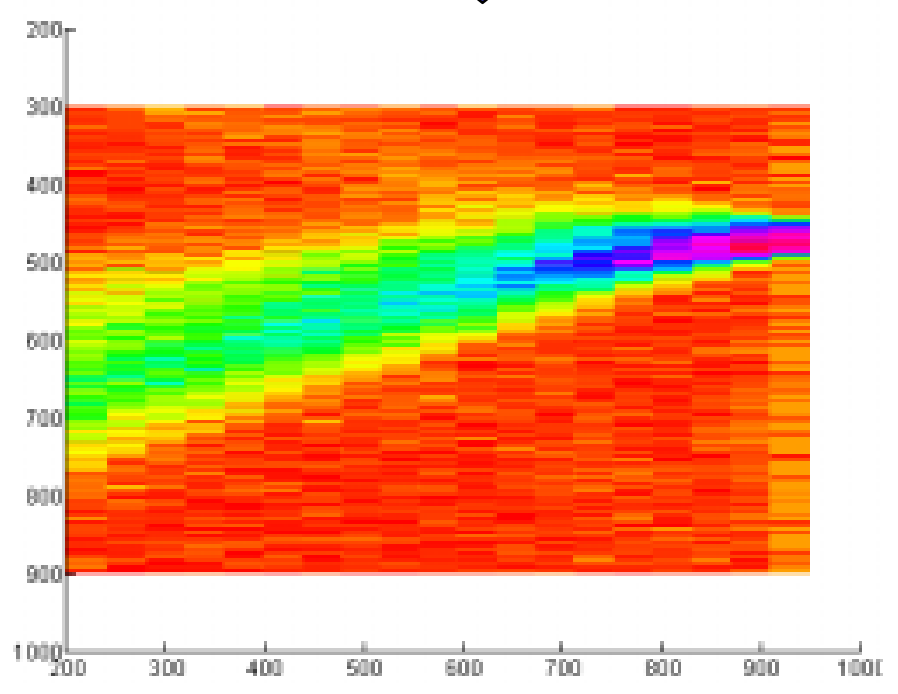




\section{Controlled Experiments}

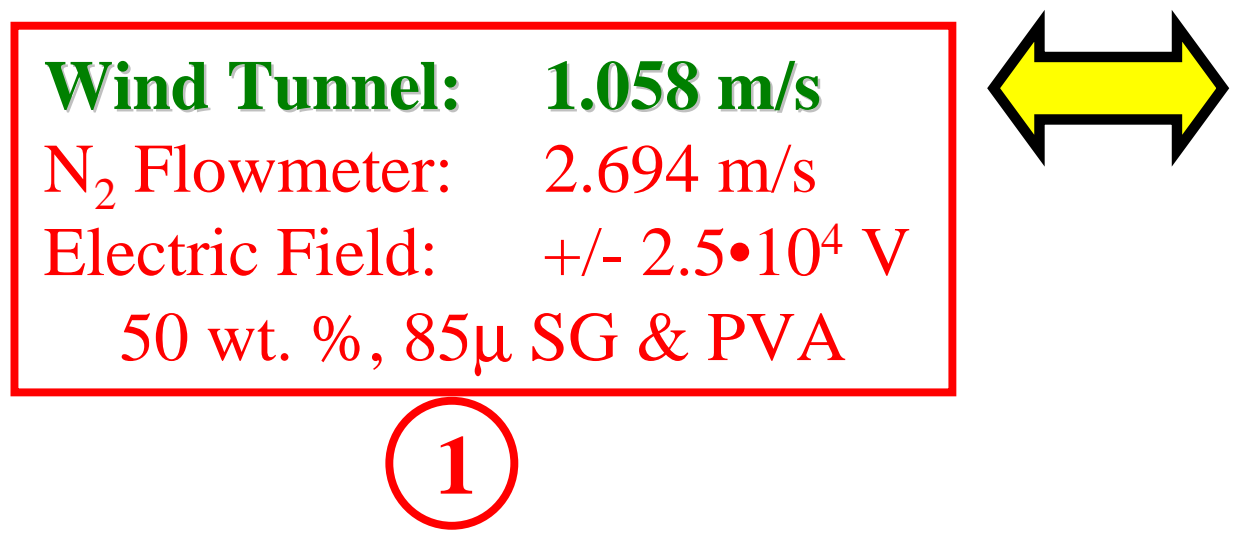

Wind Tunnel: $\quad 2.739 \mathrm{~m} / \mathrm{s}$

$\mathrm{N}_{2}$ Flowmeter: $2.694 \mathrm{~m} / \mathrm{s}$ Electric Field: $\quad+/-2.5 \cdot 10^{4} \mathrm{~V}$ 50 wt. $\%, 85 \mu$ SG \& PVA

(2)

\section{Effect of Electric Field}

Wind Tunnel: $\quad 0.413 \mathrm{~m} / \mathrm{s}$

$\mathrm{N}_{2}$ Flowmeter: $\quad 3.472 \mathrm{~m} / \mathrm{s}$

Electric Field: $\quad+/-\mathbf{2 . 5} \cdot \mathbf{1 0}^{\mathbf{4}} \mathrm{V}$

10 wt. $\% 210 \mu$ SG; 45-75 $\mu$ PVA

(3)
Wind Tunnel: $\quad 0.413 \mathrm{~m} / \mathrm{s}$

$\mathrm{N}_{2}$ Flowmeter: $\quad 3.472 \mathrm{~m} / \mathrm{s}$

Electric Field: $\mathbf{0}$ V

10 wt. \% 210 $\mu$ SG; 45-75 $\mu$ PVA

(4) 


\section{Effect of Electric Field}

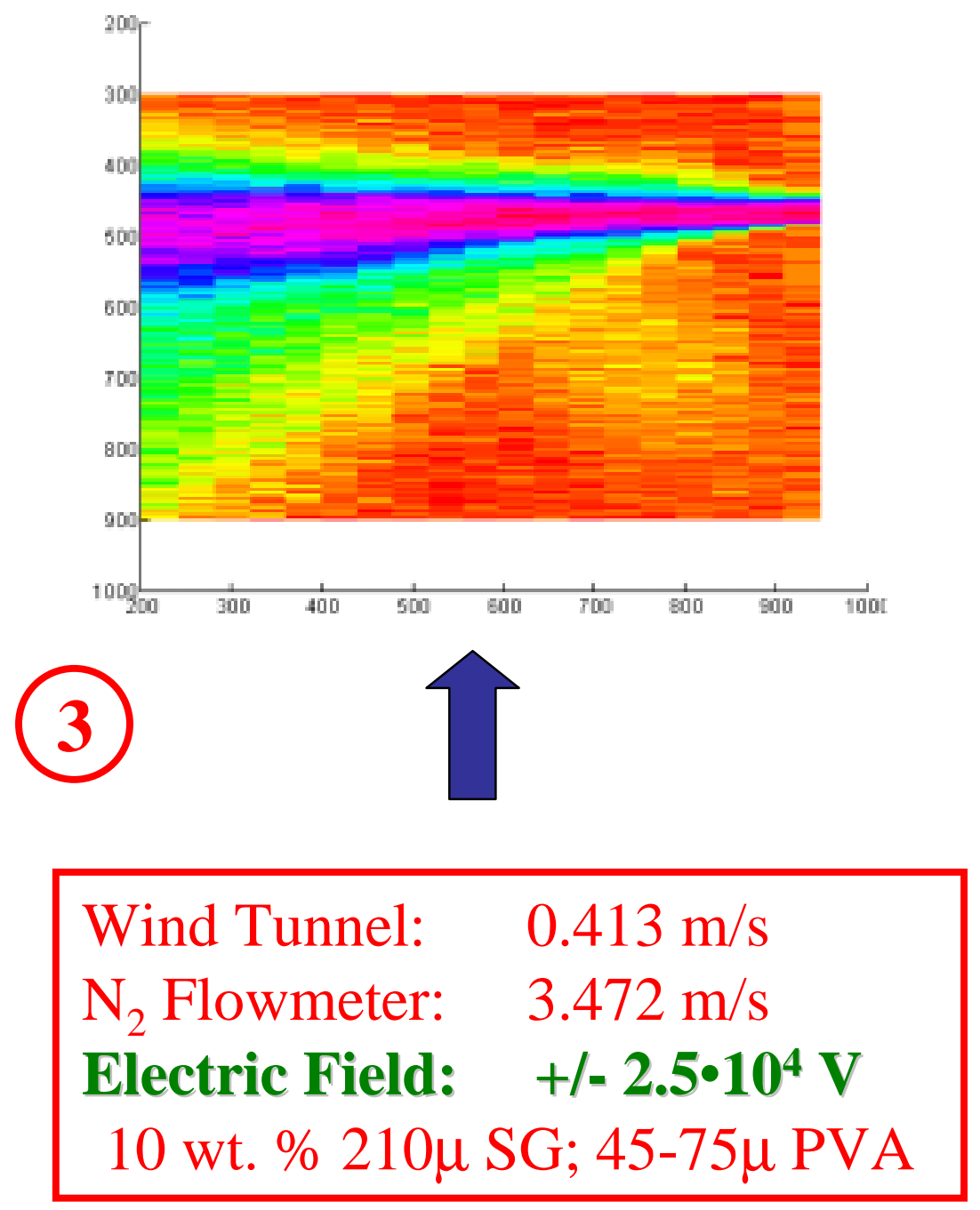

\begin{tabular}{|ll|}
\hline Wind Tunnel: $\quad 0.413 \mathrm{~m} / \mathrm{s}$ \\
$\mathrm{N}_{2}$ Flowmeter: & $3.472 \mathrm{~m} / \mathrm{s}$ \\
Electric Field: & $\mathbf{0 ~ V}$ \\
10 wt. $\%$ 210 $\mu \mathrm{SG} ; 45-75 \mu \mathrm{PVA}$
\end{tabular}

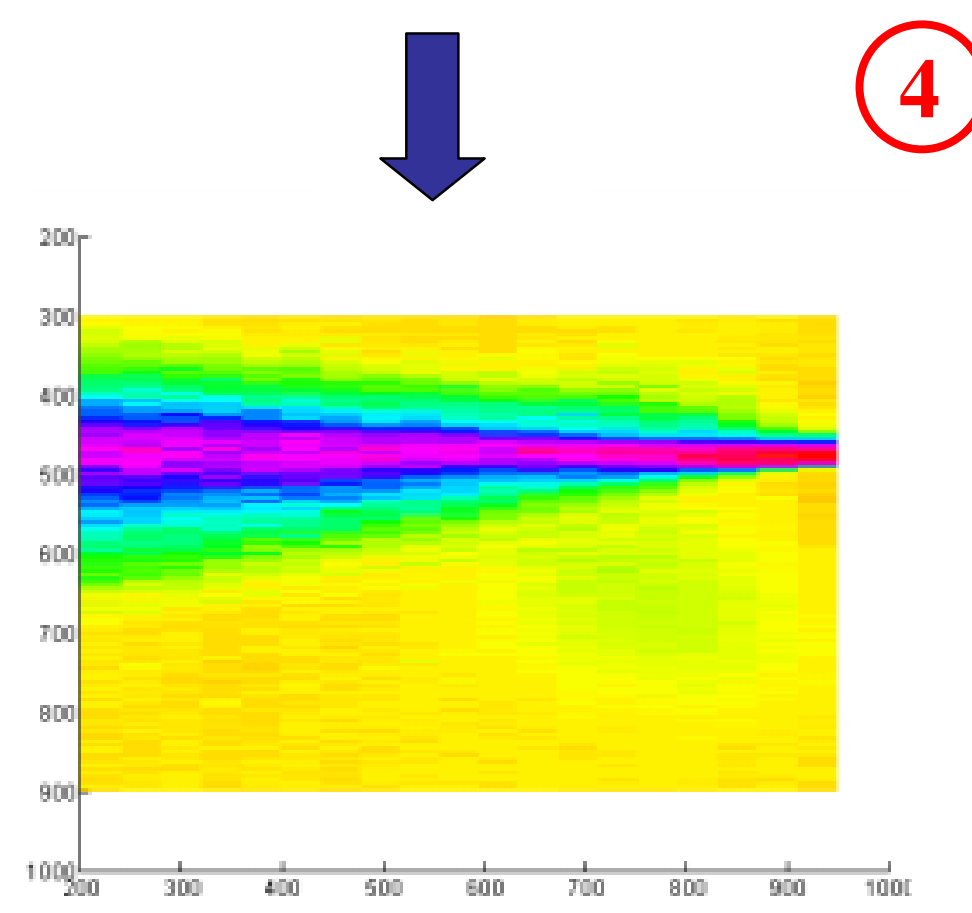




\section{Outline}

$>$ Essence of the Problem \& Application

$>$ Experimental

$»$ A History of Triboelectrostatic Separations

»Particle Flow Analysis Facility (PFAF)

»Results from the PFAF -- Experimental Results \& Animation of Particle Trajectories

$>$ Theoretical

»Probability Density Function Approach -- Qualitative

Data Interpretation

»Concentration Equation

»Moment Analysis \& Illustration 


\section{Theoretical Modeling}

Simplified Version of the PDF Approach

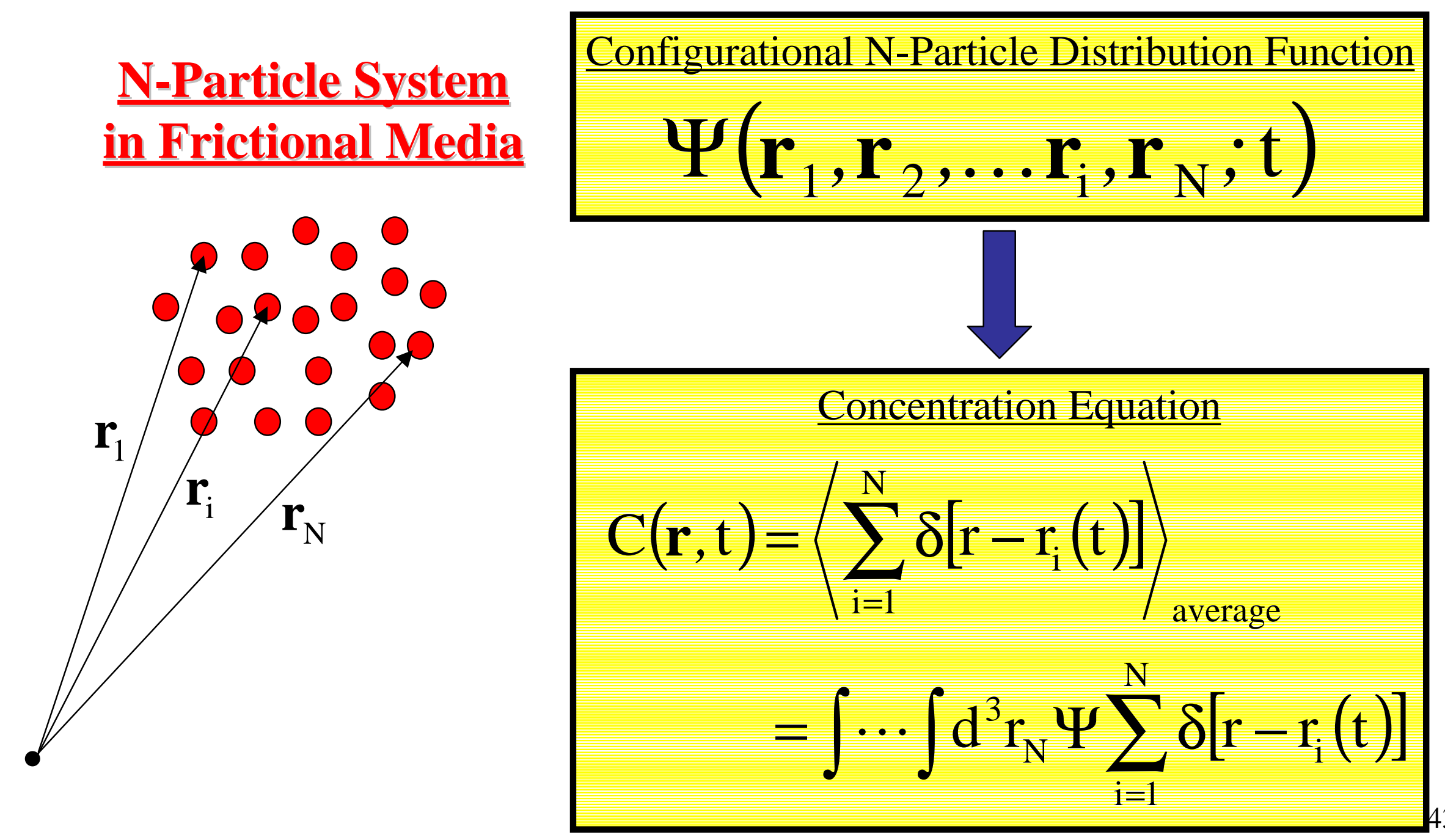




\section{Concentration Equation}

$$
\frac{\partial}{\partial \mathrm{t}} \mathrm{C}(\mathrm{r}, \mathrm{t})=\left\langle\sum_{\mathrm{i}=1}^{\mathrm{N}} \frac{\partial \mathrm{r}_{\mathrm{i}}}{\partial \mathrm{t}} \frac{\partial}{\partial \mathrm{r}_{\mathrm{i}}} \delta\left(\mathrm{r}-\mathrm{r}_{\mathrm{i}}\right)\right\rangle=-\nabla \bullet \mathrm{J}(\mathrm{r}, \mathrm{t})
$$

$$
J(r, t) \equiv\left\langle\sum_{i=1}^{N} \dot{r}_{i} \delta\left(r-r_{i}\right)\right\rangle
$$

A rigorous expression for this FLUX TERM can be obtained if $\dot{\mathbf{r}}_{\mathbf{i}}$ is given. 


\section{Moment Analysis}

$>$ Rigorous solution of the concentration equation is difficult.

$>$ We cast the space-dependent concentration into moment form:

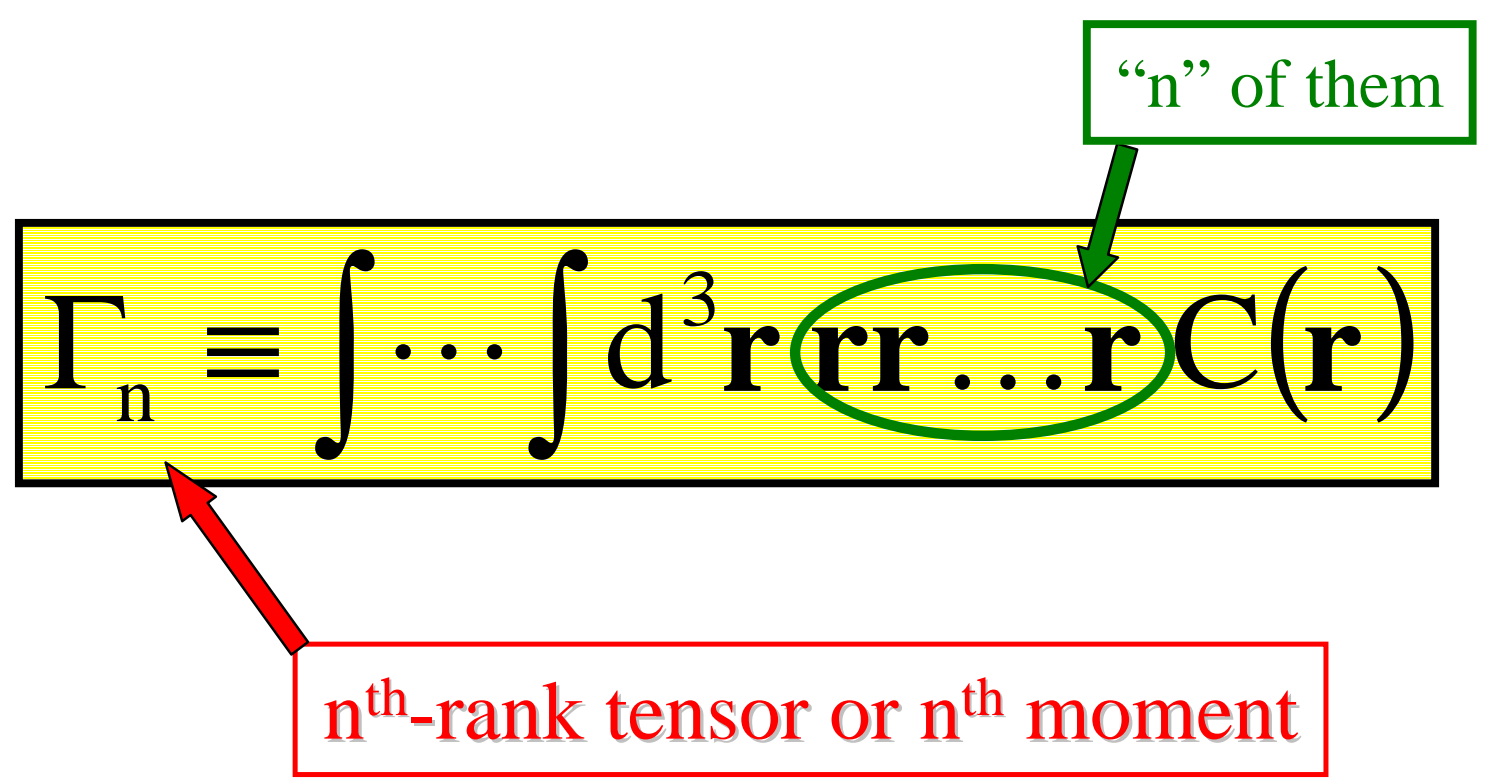




\section{Illustration of the First Few Moments}

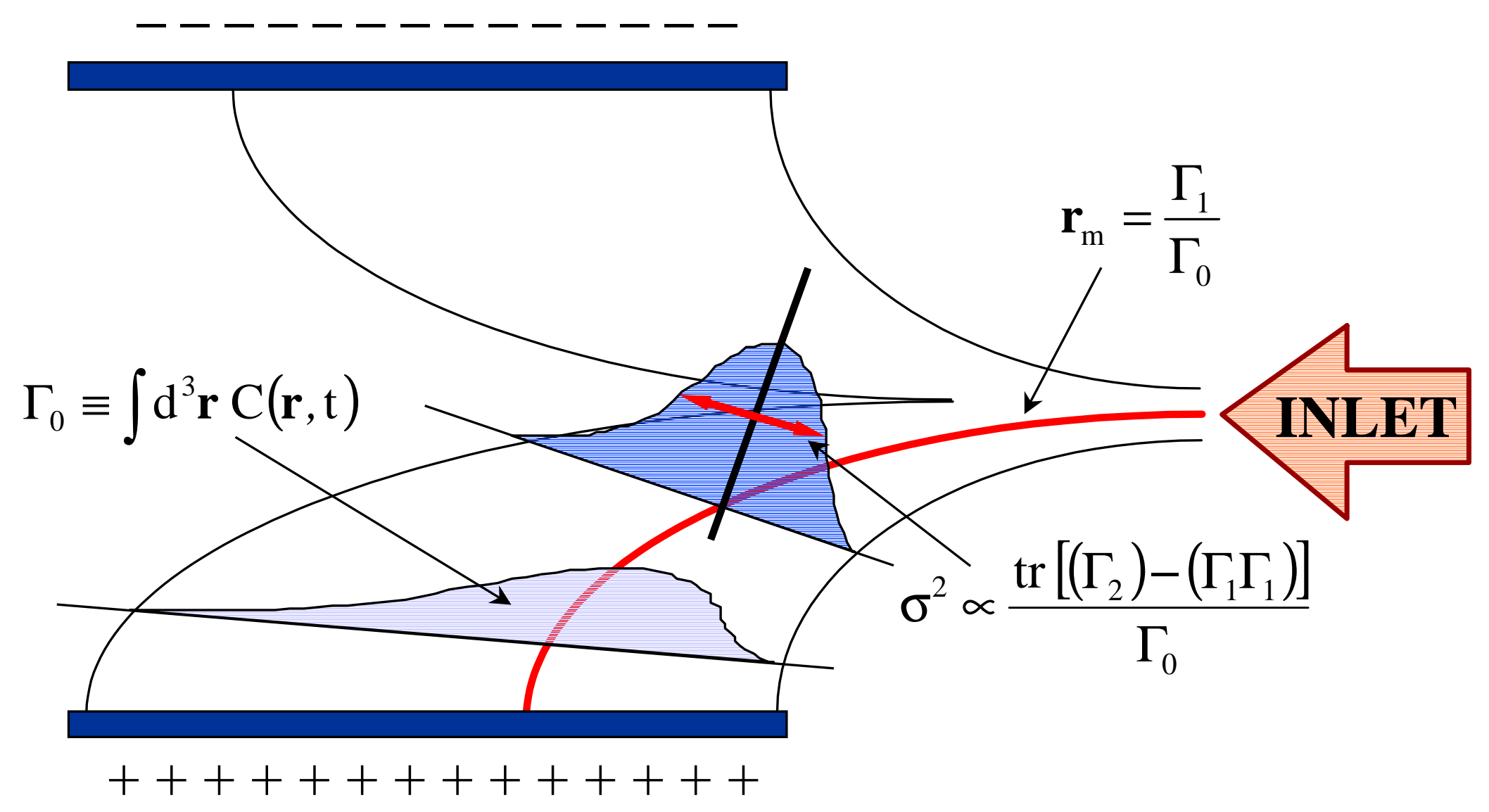




\section{Concentration Profiles - Experiment (1)}

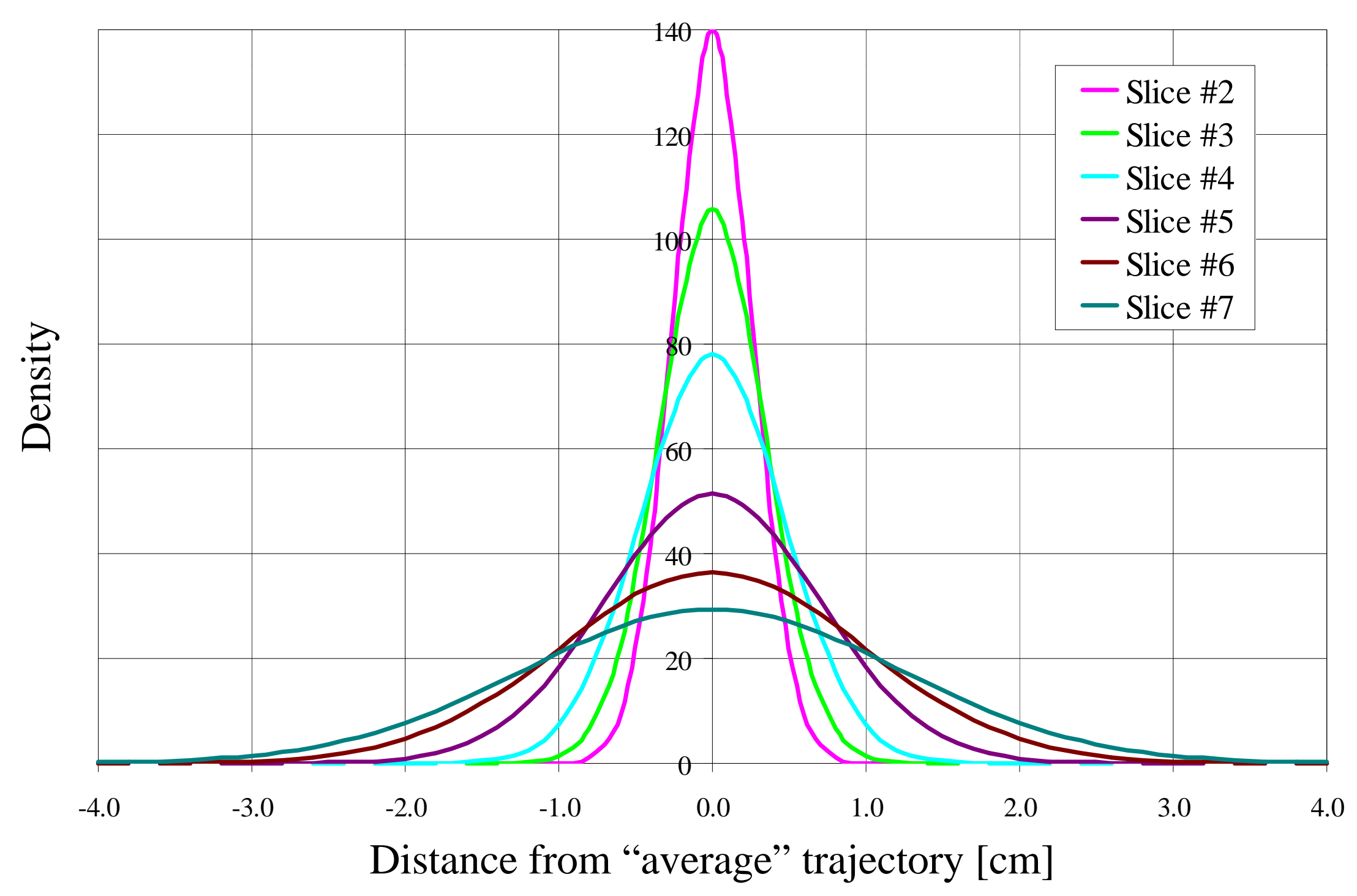




\section{Modeling Summary}

$>$ "Average Particle" Trajectory $\left(\mathbf{r}_{\mathrm{m}}\right)$ is Influenced Primarily by the External Electric Field \& Sweep Gas.

$>$ "Swarm" Dispersion $\left(\sigma^{2}\right)$ is

Primarily Influenced by Drag \&

Interparticle Electrostatic Forces. 